Revista Brasileira de Cartografia

ISSN 1808-0936 | https://doi.org/10.14393/revbrascartogr

Sociedade Brasileira de Cartografia, Geodésia, Fotogrametria e Sensoriamento Remoto

\title{
A Framework to Automatic Detect Center Pivots Using Land Use and Land Cover Data
}

\section{Sistema para Deteç̧ão Automática de Pivôs usando Dados de Uso e Cobertura da terra}

\author{
Marcos Lima Rodrigues ${ }^{1}$, Thales Sehn Körting ${ }^{2}$, Gilberto Ribeiro de Queiroz ${ }^{3}$
}

1 National Institute for Space Research. PPGCAP. São José dos Campos - SP - Brazil. marcos.rodrigues@inpe.br

ORCID: https://orcid.org/0000-0002-9199-6928

2 National Institute for Space Research. DIOTG. São José dos Campos - SP - Brazil. thales.korting@inpe.br

ORCID: https://orcid.org/0000-0002-0876-0501

3 National Institute for Space Research. DIOTG. São José dos Campos - SP - Brazil. gilberto.queiroz@inpe.br

ORCID: https://orcid.org/0000-0001-7534-0219

\begin{abstract}
Water management is currently a key field to support life and economic activity. The increased mechanization in agriculture, mainly through center pivot irrigation systems, it is a challenge, because consume the majority of hydrological resources. The Brazil is among the 10 largest in terms of irrigated area $\left(8.2 \times 10^{6} \mathrm{ha}\right)$, making monitoring essential. Thus, we present an approach based on digital image processing and machine learning for detecting center pivots. The methodology focuses on circular Hough transform (CHT) and balanced random forest (BRF) classifier using vegetation indices (NDVI/SAVI) generated from Landsat 8 images and land use and land cover (LULC) data provided by MapBiomas project. The candidate's pivots circles identified on images are filtered based on the spectral response of the vegetation and the shape characteristics of objects present in these areas. Our approach was able to detect 7358 pivots, reaching an $83.86 \%$ recall for the 52 tiles analyzed in Brazil compared with mapping performed by the Brazilian National Water and Sanitation Agency (ANA). In some tiles, the recall reached up to $100 \%$. The BRF model trained with spectral and geometric features allowed for the identification of pivots, where regions with a great amplitude of vegetation indices highlight areas with agricultural activity to the detriment of areas of native vegetation, and characteristics of the shapes from targets based on their delimitation through the High Pass Filter Sharr. The good accuracy achieved shows the robustness of the method in detecting pivots on a large spatial and temporal scale.
\end{abstract}

Keywords: Center Pivot. Circular Hough Transform. Land Use and Land Cover. Remote Sensing.

Resumo: A gestão dos recursos hídricos é fundamental para sustentar à vida e as atividades econômicas. O aumento da mecanização na agricultura, principalmente por meio de sistemas de irrigação por pivô central, é um desafio, pois consome grande parte deles. O Brasil está entre os 10 maiores em termos de área irrigada $\left(8,2 \times 10^{6}\right.$ ha $)$, tornando fundamental o monitoramento. Assim, apresentamos uma abordagem baseada em processamento digital de imagens e machine learning para identificação pivôs. A metodologia foca na transformada circular de Hough (CHT) e classificador balanced random forest (BRF) usando índices de vegetação (NDVI/SAVI) gerados a partir de imagens Landsat 8 e dados de uso e cobertura da terra (LULC) fornecidos pelo projeto MapBiomas. Os círculos candidatos a pivôs identificados nas imagens são filtrados com base na resposta espectral da vegetação e nas características da forma dos objetos presentes nessas áreas. Nossa abordagem foi capaz de detectar 7358 pivôs, atingindo um recall de $83,86 \%$ para as 52 órbitas/pontos analisadas no Brasil quando comparada ao mapeamento realizado pela Agência Nacional de Águas e Saneamento Básico (ANA). Em algumas, o recall atingiu até 100\%. O treinamento do BRF com atributos espectrais e geométricos permitiu à identificação de pivôs em áreas de cultivo devido à maior amplitude dos índices de vegetação em detrimento a áreas de vegetação nativa, e características das formas dos alvos delimitados pelo filtro passa-altas Sharr. A boa precisão alcançada mostra à robustez do método na detecção de pivôs em grande escala espacial e temporal.

Palavras-chave: Pivô Irrigação. Transformada Circular de Hough. Uso e Cobertura da terra. Sensoriamento Remoto 


\section{INTRODUCTION}

The practice of irrigation is one of the oldest techniques in agricultural production, used mainly by civilizations that developed in arid regions such as Egypt and Mesopotamia (BRITANNICA ESCOLA WEB, 2020). In Brazil, irrigation started around 1900 for rice production in Rio Grande do Sul state (ANA, 2017). However, from 1970 to 1980, there was a significant intensification of agricultural activity and mechanization in other regions, driven mainly by government programs such as the Northeast Irrigation Program (PROINE), Irrigation Equipment Financing Program (PROFIR) and National Irrigation Program (PRONI) (GUIMARÃES; LANDAU, 2014). This contributed to new national irrigation poles, which are special areas for water resource management for irrigated agriculture on a national scale because for the total irrigated area, concentration and growth are observed over the short and medium time (ANA, 2019).

Irrigation is an agricultural practice that employs a set of equipment and techniques to supply the total or partial deficiency of water for cultivation. On one hand, the use of irrigation has several advantages for agricultural production, for example, increased productivity in relation to rainfed cultivation ${ }^{1}$. On the other hand, this use changes the availability conditions of water, because the water consumed by the evapotranspiration of plants and soil does not return to water bodies. Currently, with $8.2 \times 10^{6}$ ha (ANA, 2021), Brazil is among the 10 largest countries in the world in terms of irrigation areas (FREKEN; GILLET, 2012). However, according to the Brazilian National Water and Sanitation Agency (ANA), the country still has great potential to be explored. Provisions for 2030 demonstrate that there will be a strong expansion of irrigation activity (Figure 1), mainly using center pivot systems (ANA, 2017). The center pivot system is a mechanism formed by a galvanized steel pipe suspended by towers with wheels at the base having water emitters along their length. This type of system irrigates a circular area by rotating this structure around a fixed point, called a pivot point, which serves to anchor the system and extract the water (MARANHA, 2018).

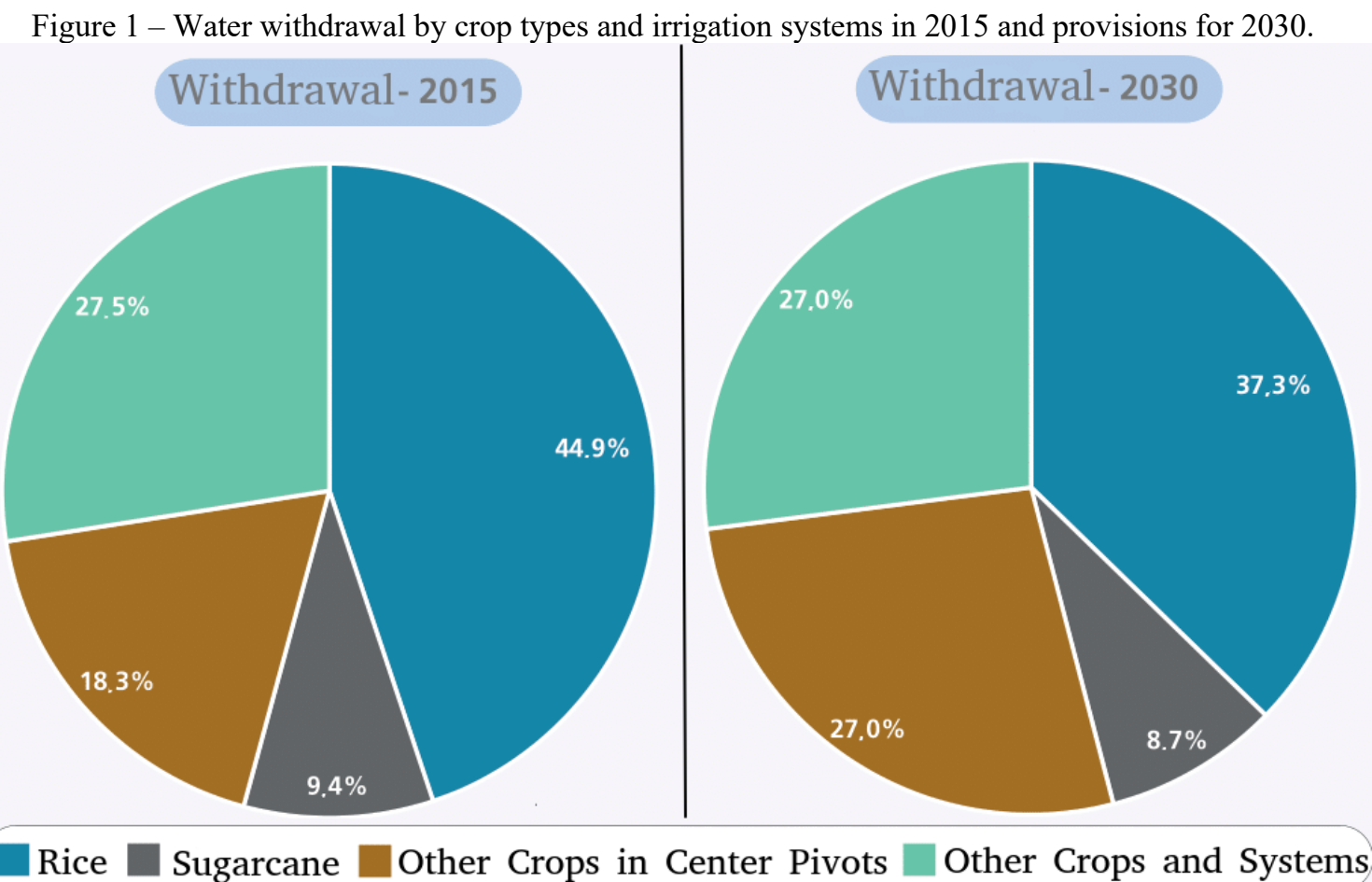

Source: Adapted from ANA (2017).

\footnotetext{
${ }^{1}$ Comparative of the productivity of rainfed and irrigated crops, source Secretariat of Water Resources of the Ministry of Environment SRH/MMA available on https://www.codevasf.gov.br/linhas-de-negocio/irrigacao/a-irrigacao-no-brasil/comparativo. Accessed on August 24, 2020.
} 
Water is a vital resource for all life on the planet. From this point of view, it is essential that irrigation activity be conducted in a sustainable manner supported by legal requirements, such as granting the right to use water resources (authorization for the use of water) and charging for use. However, due to the dynamism that irrigated agriculture presents and the continental dimensions of Brazil, the monitoring of this activity has become a great challenge (ANA, 2017).

In this sense, the use of remote sensing is recognized as a useful and effective tool for acquiring information on irrigated areas, regardless of the type of soil and climate (OZDOGAN et al., 2010), in addition to being more economical and faster than traditional statistical methods (CHEN et al., 2018). Over the past few years, ANA and collaborators have aimed to expand information about the use of irrigation in Brazil with the publication of several surveys (GUIMARÃES; LANDAU, 2014; ANA, 2016, 2019; ANA; EMBRAPA, 2019) and atlases (ANA, 2017, 2021), but all this effort usually only covers a snapshot in time and depends strongly on a component based on visual inspection by a specialist to determine the irrigated areas. According to Zhang et al. (2018), although the visual analysis of images is relatively simple, the identification and digitization for a wide range of areas can be very time and labor-consuming.

On the vast majority of studies available in the literature regarding the mapping of irrigated areas, remote sensing data are used only as a support tool associated with statistical data from official surveys or measures in situ (MARANHA, 2018), mainly for the visual analysis of satellite images to map circles of center pivots systems (SPAGNOLO; COUTO JUNIOR, 2013; TRINCA et al., 2015; MARTINS et al., 2016). Currently, with the advent of very high-resolution images and the increasing use of machine learning (ML) techniques, automatic and semiautomatic techniques for the identification and classification of fields with irrigation crops have increased (AKSOY; YALNIZ; TASDEMIR, 2012). However, most approaches are limited to small areas of study (partial scene) and specific periods of the year. For example, Santos et al. ( 2015) presented an approach to characterize areas irrigated by center pivots based on the adjustment of vegetation response thresholds using the normalized difference vegetation index (NDVI) and soil adjusted vegetation index (SAVI) for two periods (rainy and dry) in an irrigated area of the municipality of Paranapanema-SP. This type of extremely localized approach does not allow the reproducibility and generalization of the application of this methodology to other areas and regions, so much so that the values found by the authors differ from other studies proposed by Demarchi; Piroli and Zimback (2011) with the same type of approach to other regions and dates.

To handle this problem, some authors have proposed using a multitemporal approach based on time series from satellite images, which allows for determining dynamic agricultural areas with more confidence, especially when irrigation is used. These areas present continuous changes in land cover and spectral responses caused by the phenology of vegetation and harvesting (GUO; JIA; PAULL, 2018). In this sense, Son et al. (2020), using a time series from Sentinel 2, achieved great results to determine the expansion of the irrigated areas of rice in Taiwan, demonstrating the potential of this approach to provide information about rice-growing areas over large and heterogeneous regions. Another advantage of using a set of images for mapping irrigated crop areas is the possibility of providing a priori information about a given region, thus increasing the accuracy of continuous learning models without the need for many samples for fine-tuning (GUO; JIA; PAULL, 2018). The classification of multitemporal the irrigated areas also allows for monitoring over time of the consumption and depletion of water resources due to the indiscriminate use of irrigation (SHARMA et al., 2018). These approaches highlight that using a set of satellite images is crucial to the task of detecting small and large-scale changes in land cover that is normally associated with human actions such as irrigated agriculture.

In this context, some approaches have been proposed to automate the identification of pivots based on the delimitation of circular shapes in images through an edge delimiter and unsupervised classification (ZEILHOFER et al., 2007) and associated with the temporal composition of images to reinforce the vegetation response combined with morphological filters to remove noise in these maps (YAN; ROY, 2014). These approaches have as the main disadvantage a dependence on adjusting the parameters of their algorithms by a specialist to improve their performance. Recently, some studies have shown good results with the use of convolutional networks for the identification of pivots (ZHANG et al., 2018) and for 
segmentation and classification of irrigation areas (SARAIVA et al., 2020; COLLIGAN et al., 2021). However, these approaches have a disadvantage in that they depend on a large volume of data for their adoption and present some weakness to be able to generalize learning in time and space (EIRAS et al., 2020; SARAIVA et al., 2020).

Based on the aforementioned considerations, this paper proposes a novel approach based on multistage processing to locate and quantify center pivot irrigation systems based on circle detection using circular Hough transform (CHT) over images of SAVI amplitude and classification of the vegetation response and shape characteristics of targets detected using balanced random forest (BRF) ${ }^{2}$. Multistage involves the application of postprocessing steps for handling errors that increase the false-positive cases during the process of detecting circles via CHT. The main problems are false pivots detection in riparian woods areas, urban areas and vegetated fields not irrigated by pivots. These problems were handled using a mask for areas not related to agriculture based on Landing Use and Land Cover (LULC) data provided by the MapBiomas project. The objective of this work is to present a framework based on digital processing images and machine learning techniques to address different LULC patterns and climatology and to be able to detect pivots in extensive areas of different biomes. In this scope, we evaluate two possible solutions: i) BRF_ONE - model specific for each tile (path/row); ii) BRF_ALL - model incorporates learned representations of pivots characteristics for all tiles analyzed covering four regions of Brazil. This paper is an extended version of Rodrigues; Körting and Queiroz (2020a), presented in the XXI Brazilian Symposium on Geoinformatics (GEOINFO 2020).

\section{THEORETICAL BASIS}

\subsection{Vegetation Indices}

NDVI is one of the most extensively used vegetation indices to monitoring agricultural yield using vegetation properties, such as length of the growing season, the onset date of greenness and date of maximum photosynthetic activity. This way, remote sensing-based measurement is widely used to obtain phenological data in order to emphasize characteristics of terrestrial ecosystems to identify land cover and natural or anthropogenic changes (YIN et al., 2012).

Although the NDVI is highly correlated with vegetation parameters, its response can be influenced by atmosphere or substrate differences. Atmospheric turbidity generally inhibits reliable measures of vegetation and may delay the detection of the onset of stress in canopies, green leaf area, biomass, percent green cover, productivity, and photosynthetic activity (HUETE, 1988). For this reason, it is very important to combine NDVI with information from other indices, to analyze the behavior of vegetation response more carefully.

SAVI was developed to enable correction to the response of partial energy reflected from soil surface exposed when the vegetative cover is low:

$$
S A V I=\frac{N I R-R E D}{N I R+R E D+L} \times(1+\mathrm{L})
$$

where NIR is the reflectance value of the near-infrared band, $R E D$ is the reflectance of the red band, and $L$ correction factor adjusts the original equation of NDVI to correct the soil brightness. The $L$ value varies according to the presence of vegetation, very high $(L=0)$ to no vegetation $(L=1)$, but in most cases $L=0.5$ is ideal to minimize soil brightness variations and eliminate the need for additional calibration for different soils (HUETE, 1988).

\footnotetext{
2 The data and source codes used in this research are available in the Figshare repository, may be accessed at https://doi.org/10.6084/m9.figshare.c.5552382.
} 


\subsection{Circular Hough Transform (CHT)}

The CHT proposed by Duda and Hart (1972) is an approach to improve the line and curve detection on digital images derived from the idea of parameter space or Hough space (HS), originally defined by the parametric representation used to describe lines in the picture plane using the Hough transform (HT) (HOUGH, 1962). According to the authors, the general approach of the Hough method can be extended to detect circular configurations using a parametric representation for the family of all circles inside a region determined by the intersections of the circle arcs in the parameter space.

In parametric form, a circle of radius $r$ and center $(a, b)$ can be represented as:

$$
\begin{aligned}
& x=a+r \cos (\theta) \\
& y=b+r \sin (\theta)
\end{aligned}
$$

where $x, y$ are circle coordinates in image space. The angle $\theta$ sweeps through $2 \pi$ around the points $(x, y)$ tracing the perimeter of a circle in parameter space revealing the centroid (red point) of the circle in image space (Figure 2).

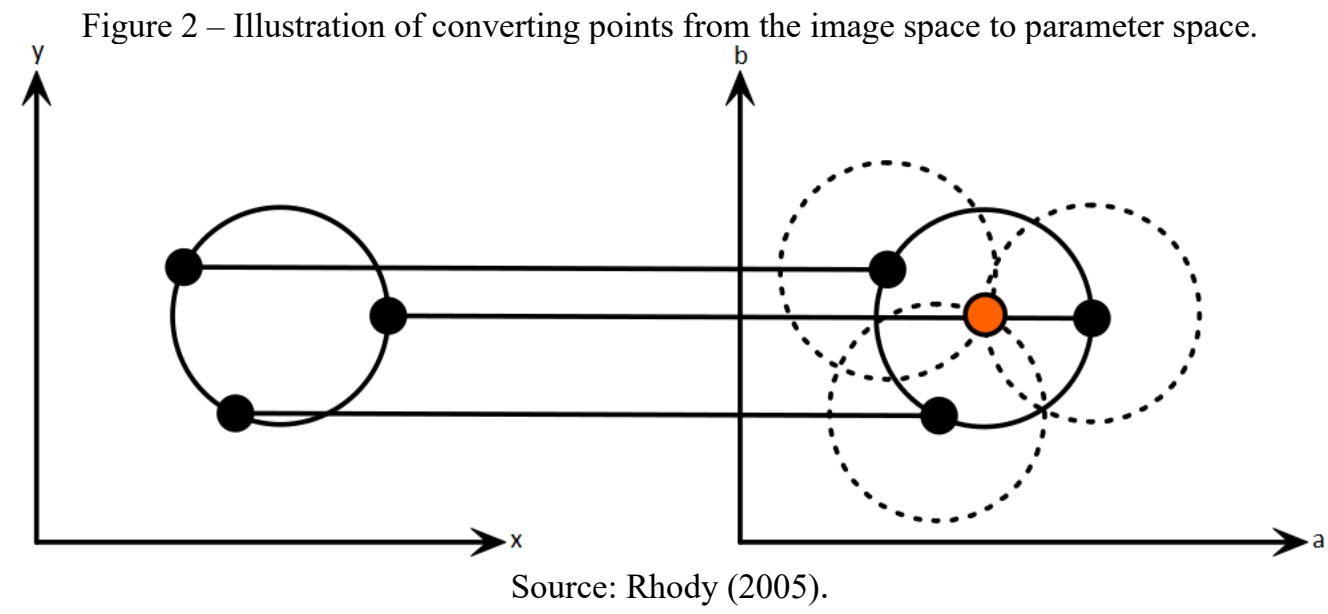

Generally, the radius of circles is unknown; then, each edge point $(x, y)$ is transformed into a circular cone in a 3D parameter space, where the accumulator array $(a, b, r)$ is defined by the dimensions of the image and a range of radii. If all the image points lie on a circle, then the cones will intersect at a single point in $(a, b, r)$ corresponding to the parameters of the circle (YUEN et al., 1989) (Figure 3). Finding for the local maximums in this space provides the identification of candidate circles in the image (DUDA; HART, 1972).

Figure 3 - Illustration of conical surface intersections, meaning a vote in a 3D accumulator array in parameter space.
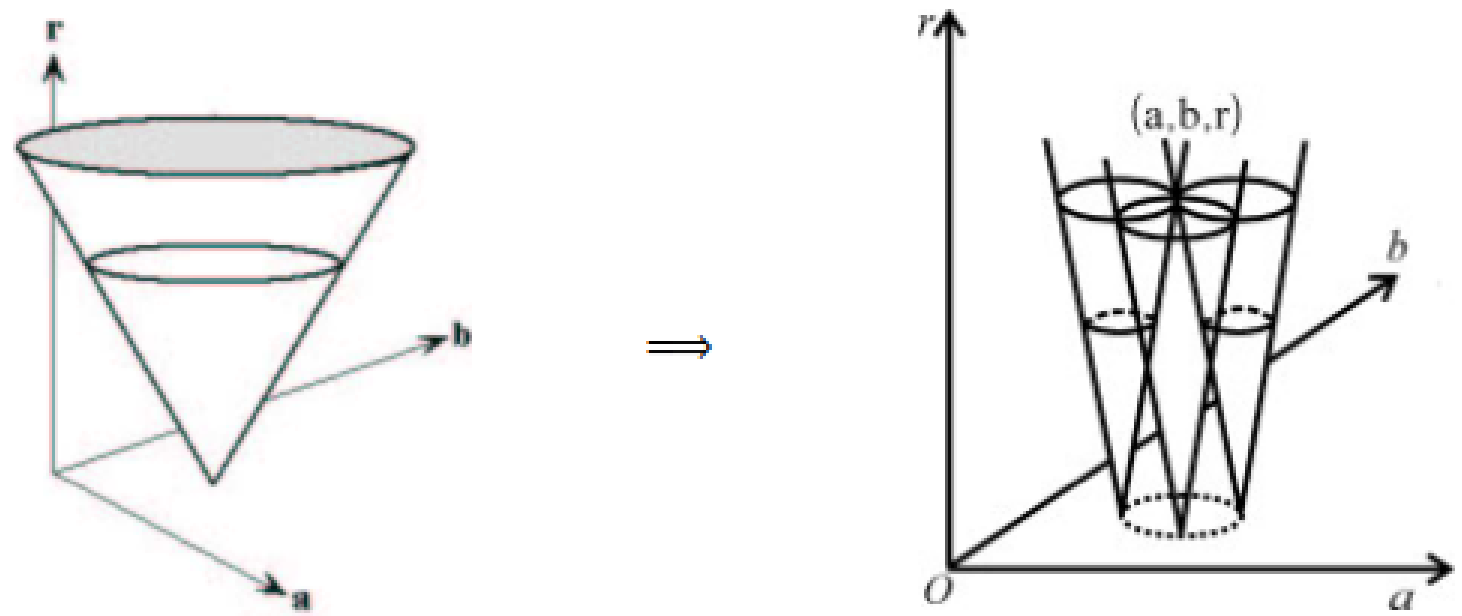

Source: RHODY (2005) (left image) and YANG et al. (2014) (right image). 
CHT is a simple feature extraction technique widely used in digital image processing for detecting circles in low-quality images (RIZON et al., 2005; DEMBELE, 2010). However, this approach requires a very large number of points to be accumulated in three-dimensional parameter space to detect circles of various sizes in images, thereby imposing excessive storage and search requirements (DAVIES, 1988). To handle this problem, Yuen et al. (1989) proposed the 2-1 Hough transform (21HT) method, which uses the gradient information of edges and decomposes the circle finding problem into two steps, thereby reducing the storage requirements.

\section{MATERIALS}

\subsection{Study Area}

Brazil has 29 irrigation poles spread over 4 regions of the country (Northeast, Central-West, Southeast and South), of which 13 exclusively employ irrigation pivots (ANA, 2019). Based on these considerations, we randomly choose 52 tiles (path/row) from Landsat 8 in these regions to test the approach in different vegetation and climatic characteristics (Figure 4). Among the chosen tiles are the areas of the municipalities that form the largest concentration of pivots in the country, Paracatu-MG, Unaí-MG and Cristalina-GO, with 2558 units reaching an area of $191 \times 10^{3}$ ha (ANA; EMBRAPA, 2019).

Figure 4 - Distribution of tiles analyzed from Brazil (left) and the cities with greatest concentration of pivots (right).
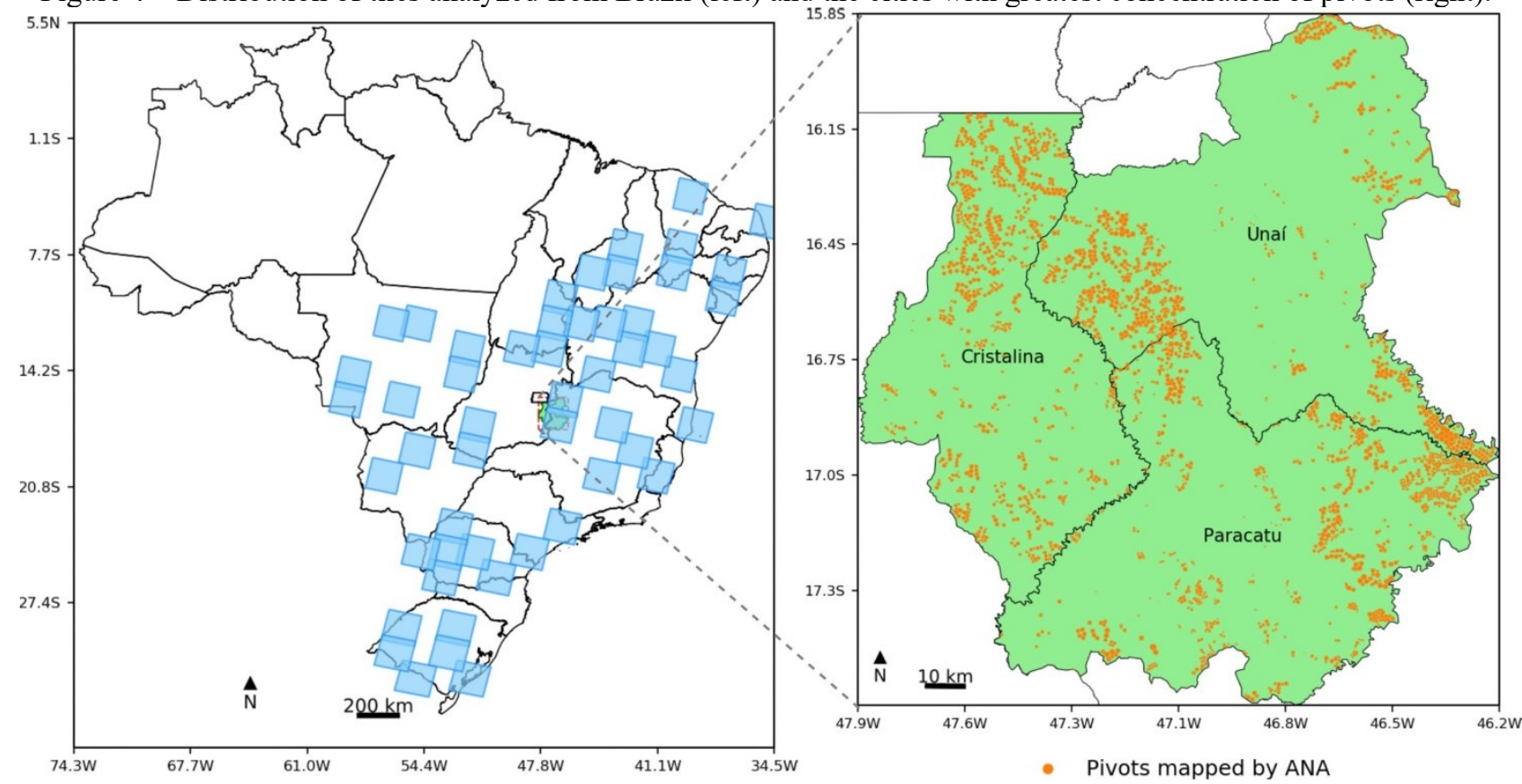

Source: The authors (2021).

\subsection{SAVI Amplitude Images}

Our work is based on the hypothesis that the amplitude obtained from the difference between the maximum and minimum vegetative responses, can highlight agricultural fields, which present a cyclical behavior of vegetative variability when compared to more stable areas, such as bare soil or forests.

In this way, we created a Python algorithm based on the application programming interface of Google Earth Engine $(\mathrm{GEE})^{3}$ to process all images available from Landsat 8 in 2017 for each path/row

\footnotetext{
${ }^{3}$ Further details about GEE API is available at https://developers.google.com/earth-engine/\#api. Accessed on: August $20,2020$.
} 
analyzed to create yearly $\mathrm{SAVI}^{4}$ Amplitudes. These images accessible at GEE correspond to the atmospherically corrected surface reflectance product from the sensor Operational Land Imager (OLI) provided by the U.S. Geological Survey (USGS) .

This collection has the product quality assessment (QA) band, which can be used to mask undesirable pixels, such as clouds, shadows and water bodies. This is necessary because vegetation indices such as SAVI or NDVI are influenced by the occurrence of clouds and cloud shadows, in certain cases producing lower values. This can make it difficult to determine the correct state of the vegetation or induce an incorrect sense of vegetation reduction (USGS, 2019).

GEE is a freely accessible, cloud-based platform designed to enable remote sensing studies over long time scales and large spatial extents (GORELICK et al., 2017). One of the main operations provided by this platform for processing image collections is the Map Reduce operation using functions from the ee.Reducer class to aggregate data over time, space, bands, arrays and other GEE structures. Therefore, it is possible to combine the images spatially and extract information, such as maximum, minimum, mean, median, and standard deviation, among others, in a time window. For example, considering the SAVI vegetation index, the result of this processing using a reducer for maximum values (Greenest Pixel) is an image with a greater photosynthetic activity in each pixel in the period (one year), which improves the detection of circular crop fields derived from the use of center pivot systems (Figure 5). The same process of aggregating data over time was used to create images of the NDVI maximum values, and all this information (NDVI/SAVI Greenest Pixels and SAVI Amplitudes) was used to extract features to train the BRF classifier and produce a final map of the detected pivots.

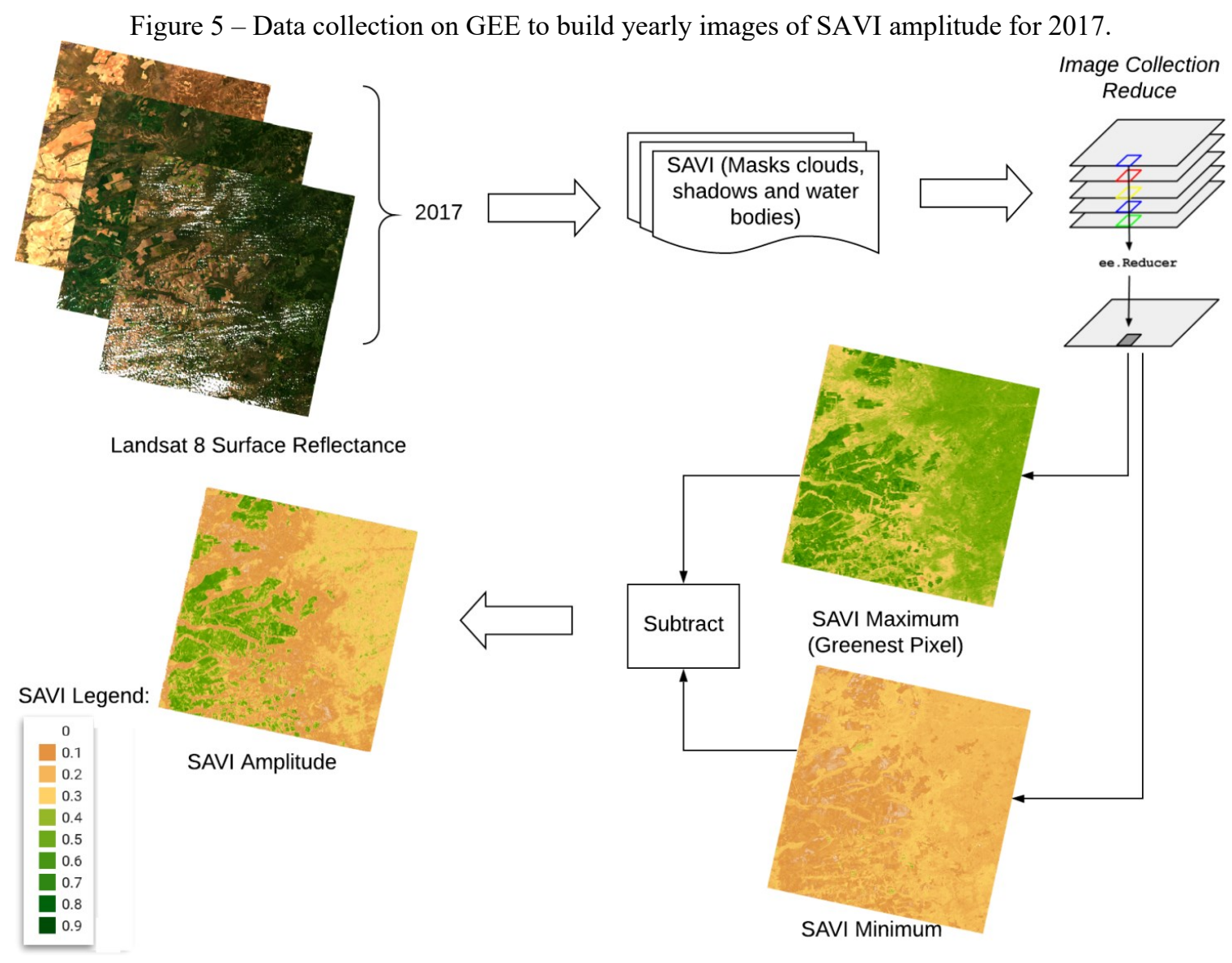

Source: The authors (2021).

\footnotetext{
${ }^{4}$ As previously mentioned, the SAVI index has a parameter for correcting the spectral response of exposed soil, which can vary between 0 and 1 depending on the soil cover. We adopt $L=0.5$ as indicated by Huete (1988).

${ }^{5}$ The Landsat 8 Surface Reflectance Tier 1 product creation involves a detailed radiometric correction of solar energy scattered and reflected from the atmosphere and earth surface processed using algorithms supplied by USGS. The catalog of images is available online at https://developers.google.com/earth-engine/datasets/catalog/LANDSAT_LC08_C01_T1_SR. Accessed on: August 20, 2020.
} 


\subsection{LULC Data}

The LULC data used in this work are provided by the MapBiomas project ${ }^{6}$, which is an initiative that involves a collaborative network with experts in biomes, land uses, remote sensing, GIS and computer science to build accurate annual LULC maps for the Brazilian territory, ranging from a 73 to $95 \%$ accuracy depending on analyzed biome (SOUZA et al., 2020).

Our approach employs these data to mask uncropped areas in each scene, avoiding pixels not belonging to the following classes: Farming, Pasture, Agriculture, Temporary Crops, Sugar Cane, Mosaic of Agriculture and Pasture, Perennial Crops, Soy Beans, Rice, Mosaic of Crops, Coffee, Citrus, Cashew and Other Temporary Crops. The edge pixels for these masked areas are removed before circle detection using CHT. For example, using this mask for path/row 220/72 reduced the number of candidate circles not related to crop areas by $80 \%$. Figure 6 shows the predominant LULC classes in this tile from areas mapped with pivots by ANA.

Figure 6 - Distribution of LULC from MapBiomas in areas with center pivots mapped by ANA for path/row 220/72 in 2017.

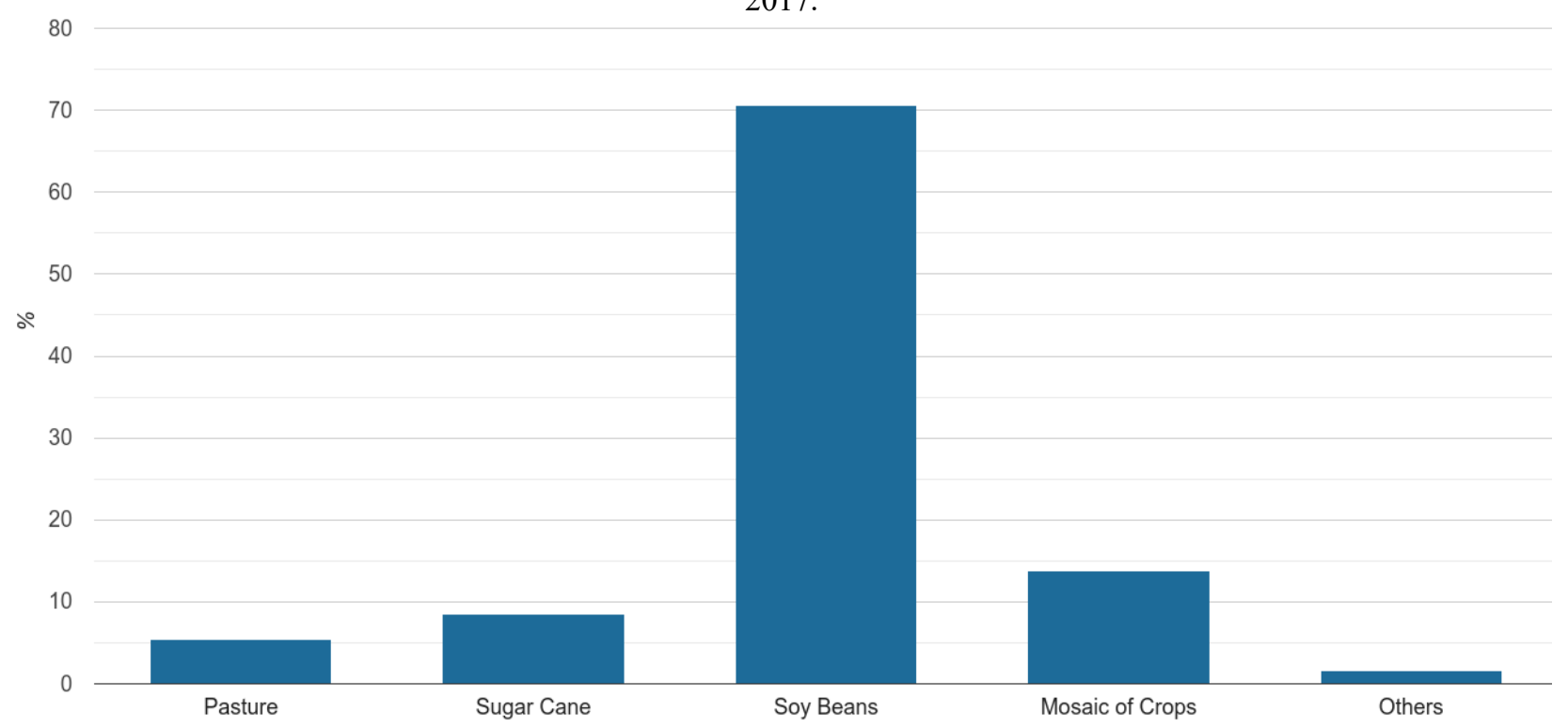

Source: The authors (2021).

\subsection{Official Information About Pivots}

Our results were validated with official information on pivots mapped by ANA, referring to 2017 . This map was produced using a visual analysis of images from Landsat, Sentinel, and other satellites. This effort to identify and quantify pivots for the country overall was performed in collaboration with the Brazilian Agricultural Research Corporation (Embrapa) and provided as a geospatial vector dataset ${ }^{7}$. According to the authors, agriculture irrigated by center pivots has shown strong and persistent growth in recent decades, mainly since 2010 , reaching an area of $1.476 \times 10^{6}$ ha with 23,181 systems. This total is 47 times greater than the area mapped in 1985 and 3 times greater than in 2000. Between 2012 and 2018, the average additional equipped area was 94 thousand ha per year, a trend that should be maintained or intensified until 2030 (ANA; EMBRAPA, 2019).

\footnotetext{
${ }^{6}$ MapBiomas Project - Collection 5 of the Annual Series of Coverage and Land Use Maps in Brazil is available online at https://mapbiomas.org. Accessed on: March 20, 2021.

${ }^{7}$ GeoNetwork is the online repository of geospatial data made by the ANA. Please refer to this address

https://metadados.snirh.gov.br/geonetwork/srv/por/catalog.search\#/metadata/e2d38e3f-5e62-41ad-87ab-990490841073 to take access to the geospatial vector dataset of center pivots. Accessed on: January 22, 2020.
} 


\section{METHODS}

Our approach uses a pair of vegetation indices to characterize vegetation density and enables the detection of crop fields irrigated by center pivots with highlighted values of the vegetation index. In addition, we also used LULC data to mask nonagricultural areas. Combining CHT and vegetation indices enables the detection of circular targets with a high response of vegetation, indicating the health of the crop due to the use of center pivot irrigation systems. Finally, we use the BRF classifier to identify true circles of pivots from candidate circles detected by CHT based on features that represent vegetation behavior (NDVI/SAVI), the type of crop (LULC) and the geometric characteristics (edges) in these areas.

\subsection{Framework for the Identification of Center Pivots}

\subsubsection{USING CHT TO IDENTIFY CANDIDATES CIRCLE OF PIVOTS}

The detection of center pivots was developed using multitemporal remote sensing data for 2017 . The first stage involves the identification of candidate circles of pivots in images through the CHT.

Generally, the process of circle detection using CHT involves preprocessing, image smoothing with a Gaussian filter to reduce noise, and edge detection to improve the accuracy of the results based on the voting process. Based on our tests, the best results (higher recall of pivots) were achieved using a high-pass filter (Sharr) to obtain the image derivatives in the $x$ and $y$ directions combined with the Canny algorithm for edge detection. The spatial image derivatives are important because they enable the identification of the edge "jump", that is, locating pixels with the maximum value of the gradient between neighboring pixels or higher than a threshold (BRADSKI; KAEHLER, 2008).

As mentioned earlier, the CHT method searches for local maximums in the parameter space, but to build and retrieve candidate circles of pivots from this space, the algorithm requires the parameters described in Table 1. The definition of the values mentioned in the table essentially depends on the spatial resolution of the image (minRadius, maxRadius and minDist) and the range of radii of the targets $(120-1000 \mathrm{~m})$, considering that typically a pivot has a radius of $400 \mathrm{~m}$ (EVANS, 2001). The sensitivityParam and the accumulator threshold (votesParam) are method-specific parameters, and the $21 \mathrm{HT}$ method has the Canny edge detector internally. In this way, the sensitivityParam will set the sensitivity of how strong the edges of the circles need to be, depending on the chosen value, which can result in a missing detection or significant clutter detection. To make the method more flexible, we decided to allow the algorithm to choose this parameter dynamically through a measure of the central tendency. After some tests, it was possible to determine the median as the best alternative to other measures, such as the mean and mode. The votesParam determines the minimum number of edge pixels in the array accumulator for peak detection (found centers of circles). For our work, this threshold value was empirically defined based on the minimum number of pixels necessary to represent a circle of radius 120 meters in the Landsat image with a spatial resolution of $30 \mathrm{~m}$.

Table 1 - Parameters adjusted to $\mathrm{CHT}^{8}$.

\begin{tabular}{l|c|l}
\hline \multicolumn{1}{c|}{ Parameter } & Value & \multicolumn{1}{c}{ Meaning } \\
\hline $\mathrm{dp}$ & 1 & $\begin{array}{l}\text { Define the size of the accumulator matrix relatively to the image } \\
\text { size. If dp=2, the accumulator has half width and height, obtaining } \\
\text { less accurate circle parameters but a stronger voting }\end{array}$ \\
\hline sensitivityParam & Depends on median of SAVI image & Value used to handle edge detection \\
\hline votesParam & 11 & The accumulator threshold for the circle centers \\
\hline minDist & 17 & Minimum distance between the center of circles detected (in pixels) \\
\hline minRadius & 4 & Minimum size of the radius (in pixels) \\
\hline maxRadius & 34 & Maximum size of the radius (in pixels) \\
\hline
\end{tabular}

Source: The authors (2021)

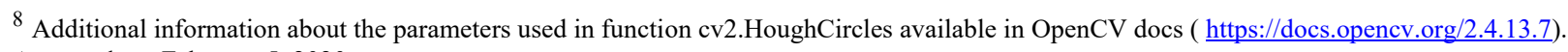
Accessed on: February 5, 2020.
} 
In our experiments it was possible to identify a trade-off in the use of the CHT method determined by the parameters used to identify the local maximums in the accumulation matrix, when defining a wide range of radii to be recovered, many candidate circles are identified which increases the percentage of agreement with real pivot points in the images. However, this also greatly increases the number of falsepositive (FP) cases that must be identified and eliminated in the next step based on the classifier to deal with unbalanced samples. This is a known drawback in detecting circles using CHT, the compromise between avoiding FP without creating false-negative (FN) cases (BARBOSA; VIEIRA, 2019).

In this work, the large number of FPs was usually associated with edges in urban areas, riparian vegetation, or crop fields not irrigated by center pivots. However, when trying to deal with this problem requiring a minimal amount of votes, we eventually created $\mathrm{FN}$ by deleting smaller radius circles that are real and present in the image. One way to address this problem is by performing a serial search for circles of a constant radius without variation and combining the response obtained at each step. This procedure significantly reduces the number of FPs that must be treated in subsequent tasks. However, this also implies a reduction of capacity to recover the pivot circles $(\approx 21 \%)$.

We decided to use a lower threshold (11 votes) for circle detection to improve recall and handle FP cases in the classification step. This characterizes our problem as a problem of unbalanced classes requiring the adoption of methods to deal with this imbalance. For each circle retrieved from HS corresponding to the response of a possible center pivot circle, a dataset containing the circle coordinates, statistical information based on vegetation indices (NDVI/SAVI) to characterize the phenological behavior of the delimited area, and information about the shape format, such as the number of edge points inside the circle and pixels compounding convex hulls, was created. This information helped determine if a target identified by CHT has or does not have a circular shape.

\subsubsection{FEATURE EXTRACTION}

For each processed tile a set of circles is generated as a result of the CHT method applied over the yearly SAVI amplitude image. The areas of these candidate's circles are then examined to extract the features needed to support the classifier to detect circles of pivots based on vegetation health and distribution (mean value and standard deviation of the vegetation indices NDVI/SAVI Greenest Pixel and SAVI Amplitude), type of crop (mode value of LULC) and geometric characteristics of the targets (radii of the circle, number of edge pixels inside of circle - PixelsWithin and percentage difference of points - DifPoints as illustrated in Figure 7, where the DifPoints values are obtained per percentual difference between all edge pixels (boundary and inside of the circle) and convex hull pixels. This feature is a good indicator to detect circles not linked to pivots because pivot areas are expected to have a homogeneous land cover (vegetation) without internal artifacts. Normally, values of DifPoints $>97 \%$ and PixelsWithin $>500$ (depending on radius) are associated with non-pivots. 
Figure 7 - Scene of Landsat 8 (true color) on May 30, 2017. Focus on an area with the detection of candidate circles of pivots by CHT and illustration of the statistical information extracted from these polygons.

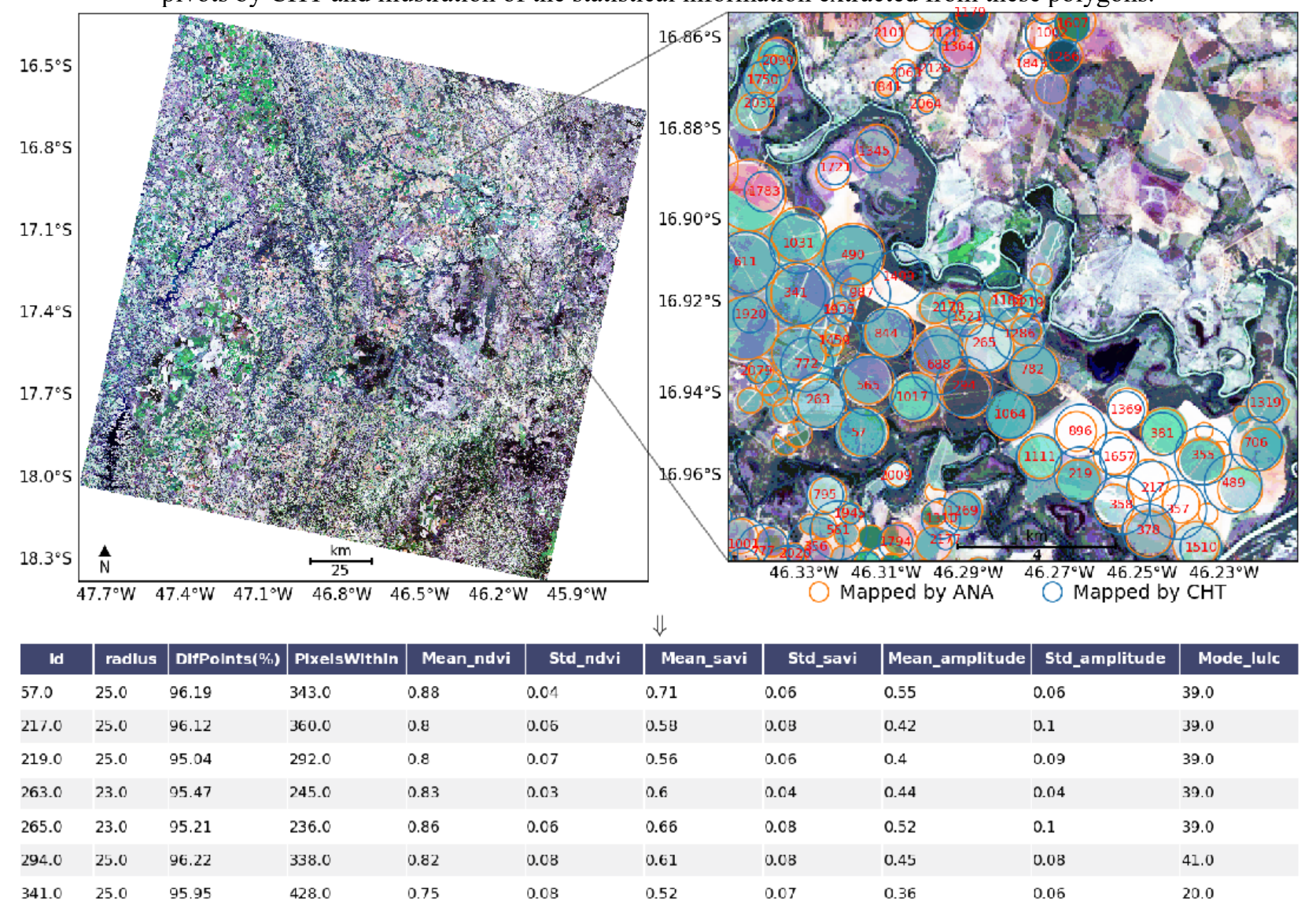

Source: The authors (2021).

All information generated during the analysis of circles builds a dataset that after being labeled serves as input to train the classification model. As a result, after classification all the samples (circles) that received a positive indication of the pivot are saved on a geojson file for validation with pivots mapped by ANA.

\subsubsection{BALANCED RANDOM FOREST (BRF) TO FILTER FALSE CIRCLES OF PIVOTS}

In a general sense, ML methods can produce good models representing the space of features from all data available. Essentially, the feature is a numeric representation of raw data. In our case, we have ten features (statistics) that have the purpose of representing both the spectral vegetation behavior and geometry characteristics on areas of the targets identified by CHT. As already explained, a set of statistical information created from targets identified by CHT can have a predominance of non-pivot circles, which characterizes our problem as an imbalanced class classification problem. It is necessary to handle this problem because the learning and prediction of ML models are usually affected by the imbalance problem of a dataset (LEMAÎTRE; NOGUEIRA; ARIDAS, 2017).

Our approach employs the random oversampling (ROS) technique combined with the BRF classifier to handle this problem (second stage), where both are part of the imbalanced-learn Python package. Essentially, ROS uses a naive strategy to generate new samples of the dataset by randomly sampling the currently available samples (upsampling). The BRF is an ensemble-type classifier, in which each tree of the forest will provide a balanced bootstrap sample (inner balancing samplers) (CHEN; LIAW; BREIMAN, 2004).

Figure 8 shows the steps to retrieve the candidate circles of center pivots ( $x, y$, radius), label the statistics extracted from candidate circles, classify using BRF and save pivots identified to compare with our official information of pivots from ANA. 
Figure 8 - The framework for center pivot identification using CHT, LULC data and the BRF classifier.

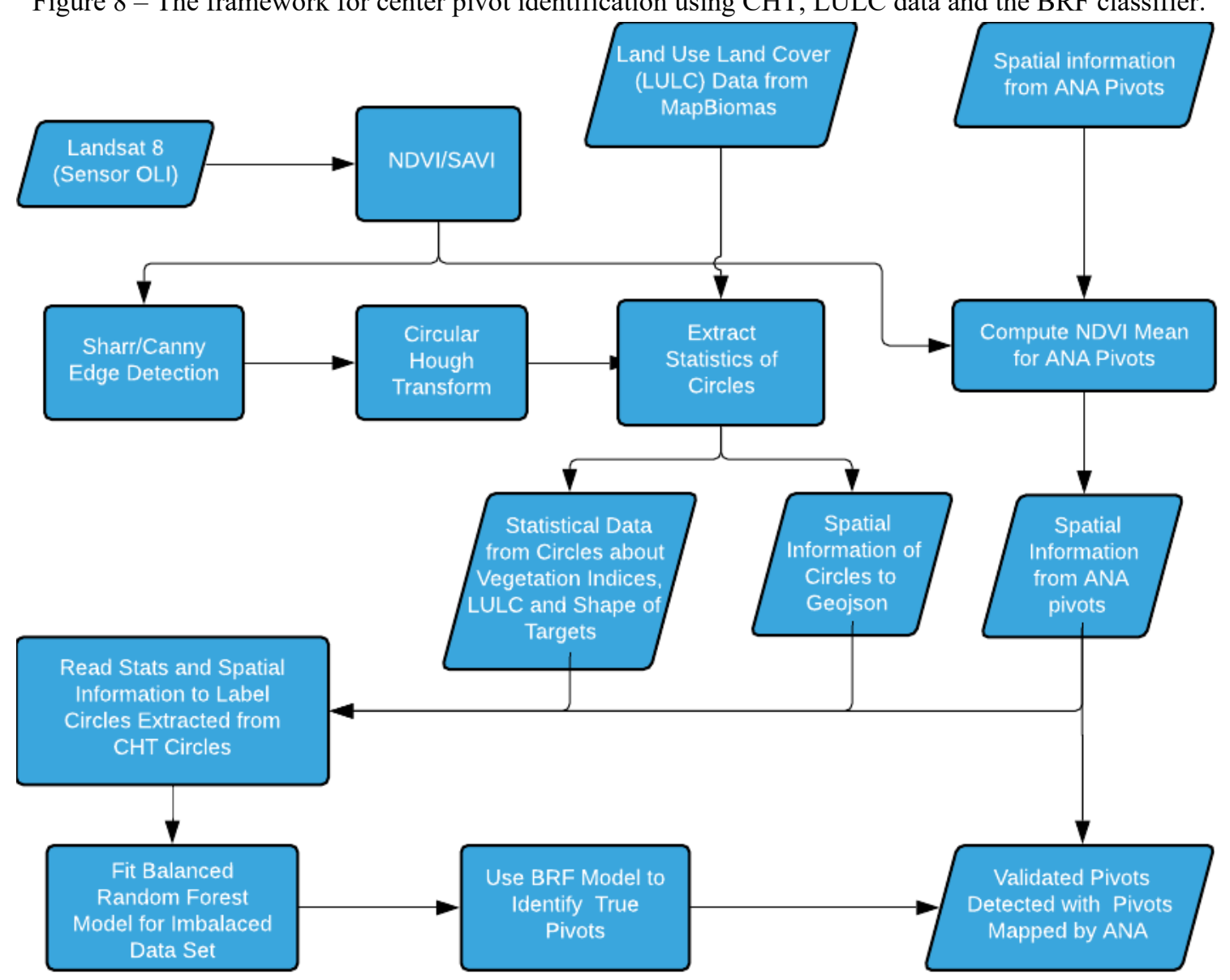

Source: The authors (2021).

The major work consists of the following steps: i) Apply the CHT method over Sharr edge detection results from the vegetation index images (SAVI Amplitude) to identify possible circles of the center pivots; ii) Perform spatial operations (intersects/within) using the library Geopandas of Python to identify which of these circles truly related to pivots, based on pivots mapped by ANA. This identification is used to label the statistical information generated from these targets either in pivot or not in pivot; iii) Fit a BRF model with labeled data to filter false alarm circles of pivots; and iv) Validate filtered circles with ANA information.

The effectiveness of our method is subject to the ability to delimit the targets (pivot areas) through the edge detection algorithm. The shape of the pivot and the response of the vegetation in these areas, estimated through vegetation indices, vary significantly as a result of the development phases of the crop from planting until harvest.

NDVI is a common and widely used remote sensing index to understand how plants grow and develop. To determine the density of vegetation, distinct wavelengths (red and near-infrared) reflected by the plant are observed. Defined as the normalized difference between these bands, its typical values vary between -1 and +1 , where positive values are associated with different vegetation densities and negative values (or zero) are associated with water bodies, urban areas and bare soil (BID, 2016).

Based on these considerations, we decided to evaluate only those circles that had an average NDVI $>0.5$, i.e., a threshold normally associated with dense vegetation (GANDHI et al., 2015; HASHIM; ABD LATIF; ADNAN, 2019). This made it possible to identify areas with the greatest photosynthetic activity, improving the delimitation of crop fields and allowing better identification of center pivots. 


\subsubsection{FEATURE SELECTION}

The BRF is based on classical random forest algorithm proposed by Breiman (2001), which creates decision trees on randomly selected data samples, gets predictions from each tree and selects the best solution by means of voting. The trees creation process is guided by the measure of feature importance through the mean decrease impurity (MDI) method, which has two limitations (LOUPPE et al., 2013; SCORNET, 2020):

a) impurity-based importances build by MDI are biased towards high cardinality features which means that numerical features have importance inflate against categorical features, which may lead to overfitting of the model;

b) impurity-based importances are computed on training set statistics - this limits the ability of feature to be useful to generalize the model to the test set.

To improve our results with the BRF model we adopted the feature selection optimized to our data using the method SelectKBest implemented in the Scikit-learn library. This method determines from $k$ features the highest-scoring based on the univariate statistical test (ANOVA F-Test), this test basically estimate the degree of linear dependency between two random variables ${ }^{9}$. The Figure 9 shows results achieved in each $(k)$ step of feature selection, means that from ten feature available which is the best ranked when $k=1$, which two related features best ranked when $k=2$ and so on. For each step features selected are validated using training accuracy of RF classifier for our data composed to more than $40 \times 10^{3}$ samples (rows with circles statistics information) for each tile on average.

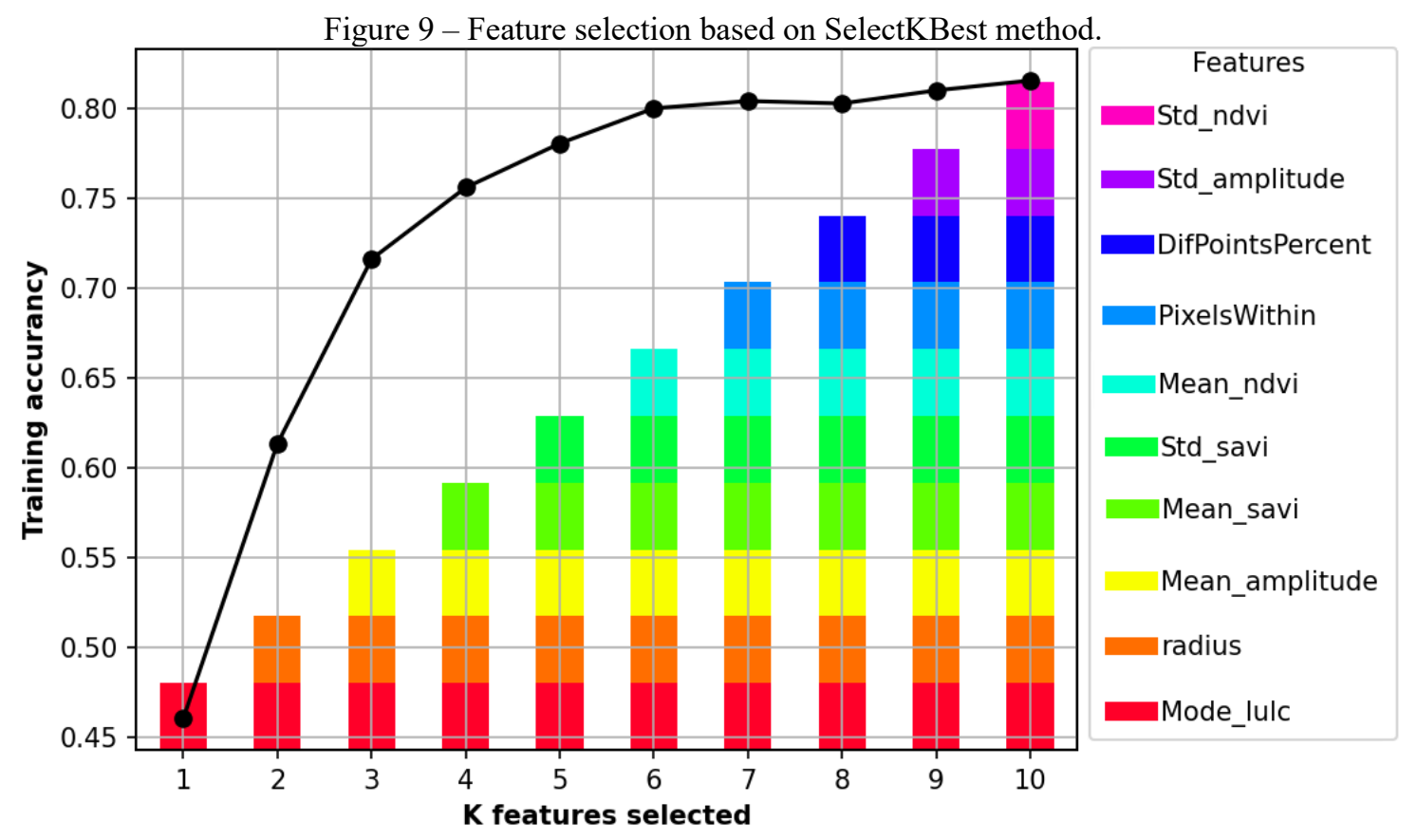

Source: The authors (2021).

Among all features, the best ranked was the mode value of LULC information, after this, the radius information is included providing an improvement of $33.20 \%$ of the accuracy. In this case, the best number for feature selection was $k=10$ with maximum accuracy achieved of $82 \%$.

Our approach aims to evaluate the performance of BRF model to classify statistics information of candidate circles to identify the true localization of pivots in remote sensing images. The tests were conducted using both one classifier per tile (BRF_ONE) as well as a single classifier with data of all tiles (BRF_ALL).

\footnotetext{
${ }^{9}$ Further information about the method is available at https://scikit-learn.org/stable/modules/feature_selection.html\#univariate-feature-selection. Accessed on: February 5, 2021.
} 


\subsubsection{MODEL TRAINING AND EVALUATION METRICS}

The BRF model was trained using a 100 -fold cross-validation approach ${ }^{10}$ to obtain smoother mean testing and training score curves, where each iteration with $20 \%$ of the data was randomly selected as a validation set. Figure 10 shows the learning results of training and cross-validation scores to classify and identify pivots on path/row $220 / 72$ using subsets $(10 \%, 33 \%, 55 \%, 78 \%$ and $100 \%)$ of samples, i.e., spectral and geometrical information extracted from candidate circles of pivots created by CHT. This tile has 17316 candidate circles, where only $12.84 \%$ of these circles are truly center pivots, with upsampling the total number of samples (pivots/not pivots) reaching 30476 examples perfectly balanced. This example demonstrates that the ROS (upsampling) technique combined with the BRF classifier considerably increased the accuracy of the model and consequently the results of the classification and identification of the pivots.

Figure 10 - Learning curve results for classification (pivots/not pivots) in path/row 220/72 using BRF varying the number of training samples.

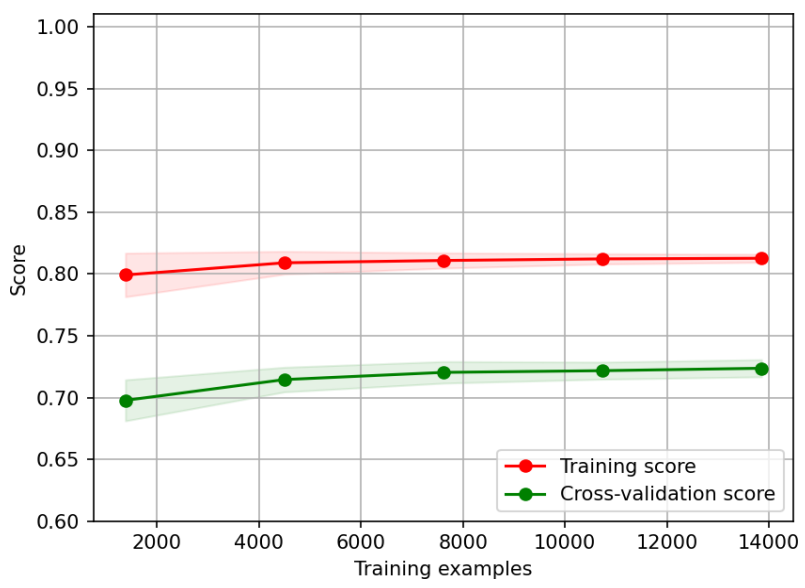

(a) Without Upsampling

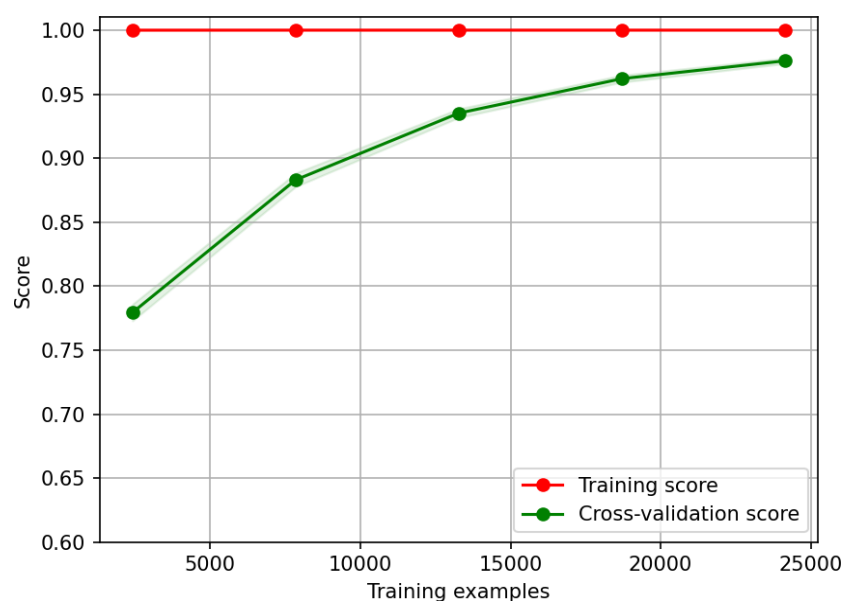

(b) With Upsampling

Source: The authors (2021).

Processing was performed on a machine with 39 cores and 1 TB of memory. Training and predicting with the BRF model took a few seconds for each tile $\left(\approx 40 \times 10^{3}\right.$ samples $)$. However, the iterative process for extracting the statistics for each circle identified by the CHT method can reach $132 \mathrm{~min}$ for a tile. Using the multiprocessing module from Python allowed us to reduce that time to $1 / 3$ by executing the extraction function in multiple threads occupying all cores at the same time.

In this study, the performance of the models was evaluated in terms of their ability to identify which circles (polygons) detected by the CHT method truly corresponded to pivots. In this sense, the following metrics were used: recall Eq. (3) and the false alarm ratio (FAR) Eq. (4). Essentially, recall means the number of pivots recovered in each tile, where the FAR percent of pivots identified by BRF does not match our reference data. Thus, the true positive (TP) cases correspond to circles classified as pivots (P) that intersect with the centroids of the pivots mapped by the ANA (\#ground truths), while FP corresponds to the same class $P$ that does not intersect. It is important to mention that the CHT method can generate overlapping circles because there is a trade-off between the necessity to detect small and large pivots radii (120 to $1000 \mathrm{~m}$ ). This condition can result in the identification of duplicates and circles that intersect more than one polygon of the ground truth reference. This explains why the FAR is low, even when the number of pivots identified by our method differs from the number of ANA pivots.

$$
\text { Recall }=\frac{T P \times 100}{\# \text { ground thuths }}
$$

\footnotetext{
${ }^{10}$ Cross-validation (CV) is an attractive strategy for model selection. Basically, CV split data several times to obtain the accuracy of each adjusted model: The training data (part of samples) is used for training (tuning step) of the model, and the validation samples (remaining part of data) is used to estimating the performance of the model (accuracy). Then, CV selects the model with the better performance achieved (ARLOT; CELISSE, 2010).
} 


$$
F A R=\frac{(P-\text { Recall }) \times 100}{P}
$$

\section{$5 \quad$ RESULTS}

To evaluate the performance of the proposed approach, we used a set of BRF classifiers adjusted for each tile analyzed (52 - BRF_ONE) and one for all tiles (BRF_ALL). The number of samples available for fitting and testing of the models ranged from approximately 500 to 73,000 depending on the tile, and combined samples for the 52 tiles achieved over 1 million. Table 2 summarizes the results presenting the scores of our 5 highest/lowest agreements in the number of pivots and evaluation metrics. The qualitative results are shown in Figure 11 and Figure 12.

Table 2 - Results based on 5 (highest/lowest) values of the pivots agreement between CHT+BRF detection and mapping by ANA.

\begin{tabular}{|c|c|c|c|c|c|c|c|c|}
\hline \multirow{2}{*}{ Path } & \multirow{2}{*}{ Row } & \multirow{2}{*}{ Mapped by ANA } & \multicolumn{3}{|c|}{ BRF_ALL } & \multicolumn{3}{c|}{ BRF_ONE } \\
\cline { 4 - 10 } & & & Pivots Identified & Recall (\%) & FAR (\%) & Pivots Identified & Recall (\%) & FAR (\%) \\
\hline & 72 & 2575 & 2642 & $\mathbf{8 8 . 8 9}$ & $\mathbf{0 . 0 8}$ & 2224 & 88.62 & 0.09 \\
\hline 220 & 71 & 1105 & 1432 & $\mathbf{9 2 . 5 8}$ & 0 & 1020 & 92.13 & 0 \\
\hline 220 & 68 & 646 & 601 & 93.19 & 0.17 & 601 & 93.34 & 0.17 \\
\hline 220 & 77 & 780 & 586 & 85.51 & 0 & 596 & 86.92 & 0 \\
\hline 217 & 69 & 613 & 479 & 78.30 & 11.46 & 479 & 78.30 & 11.46 \\
\hline 225 & 73 & 6 & 6 & 100 & 0 & 6 & 100 & 0 \\
\hline 219 & 66 & 5 & 4 & 80.00 & 0 & 4 & 80.00 & 0 \\
\hline 217 & 73 & 8 & 3 & 37.50 & 0 & 3 & 37.50 & 0 \\
\hline 226 & 74 & 5 & 2 & 40.00 & 0 & 2 & 40.00 & 0 \\
\hline 216 & 70 & 6 & 1 & 16.67 & 0 & 1 & 16.67 & 0 \\
\hline
\end{tabular}

Source: The authors (2021)

Figure 11 illustrates the results achieved for path/row 220/72. Using the procedure based on the fit model by tile (BRF_ONE) achieved recall of $88.24 \%$ against $88.89 \%$ from the BRF model fitted using samples of all tiles (BRF_ALL). This tile has 2575 pivots mapped by ANA. BRF_ALL identified 2642 pivots, of which 2289 matched with ANA pivots, while BRF_ONE identified 2224 pivots, of which 2222 matched with the official data.

As we explained earlier, the CHT method can detect overlapping circles; for this reason, the total pivots identified by our approach include polygons with multiple intersects with pivots mapped by ANA. Therefore, despite identifying more pivots than the number of pivots mapped, the recall only reflects the pivots that truly overlap the official data. This can be verified when we compare the above highlighted areas of Figure 11 (a) and Figure 11 (b), where it is possible to perceive that the BRF_ALL model has a better performance to correctly detect the pivots (blue polygons) than the BRF_ONE.

On the other hand, in terms of FAR using BRF_ALL, the value achieving $\approx 0.08 \%$ reflects the pivots identified that do not intersect pivots from ANA, which in this case is only 2 pivots. Using BRF_ONE, the FAR value of $\approx 0.09 \%$ is because of the 2224 pivots identified, and only 2 do not intersect with pivots from ANA (see the highlighted areas of Figure 11(a) and Figure 11(b)).

Considering the overall results (Figure 12) the approach based on BRF_ALL obtained the best results. From the 8774 pivots mapped by ANA in all tiles, the model correctly identified 7358 pivots (recall $83.86 \%$ and FAR $1.60 \%$ ), while BRF_ONE was able to correctly identify 6810 pivots (recall $77.46 \%$ and FAR of $7.47 \%)$.

These results emphasize that the model considering all samples can generalize better than the model for each tile. Although this class of algorithms (random forests) cannot be intrinsically interpretable because their prediction results descend from averaging several hundred decision trees, the computing variable importance is the way to obtain insight into the impact of each input variable on the prediction because this information is used to rank and select the features during the creation of the decision trees (SCORNET, 
2020).

In this context, we decided to compute the variable importance based on MDI (Figure 13) to show what features were responsible for recall $(8.26 \%)$ and FAR $(366.8 \%)$ improvements achieved with the BRF_ALL model over BRF_ONE. The main characteristic of this type of model employing tree ensemble methods is to handle high-dimensional tabular datasets, producing results with a notable predictive accuracy (LOUPPE et al., 2013).

Figure 11 - Pivot identification using CHT+BRF on yearly SAVI amplitude images (2017) from path/row 220/72. Blue polygons are correctly identified pivots, red polygons are false alarms and orange polygons are official pivots not identified.

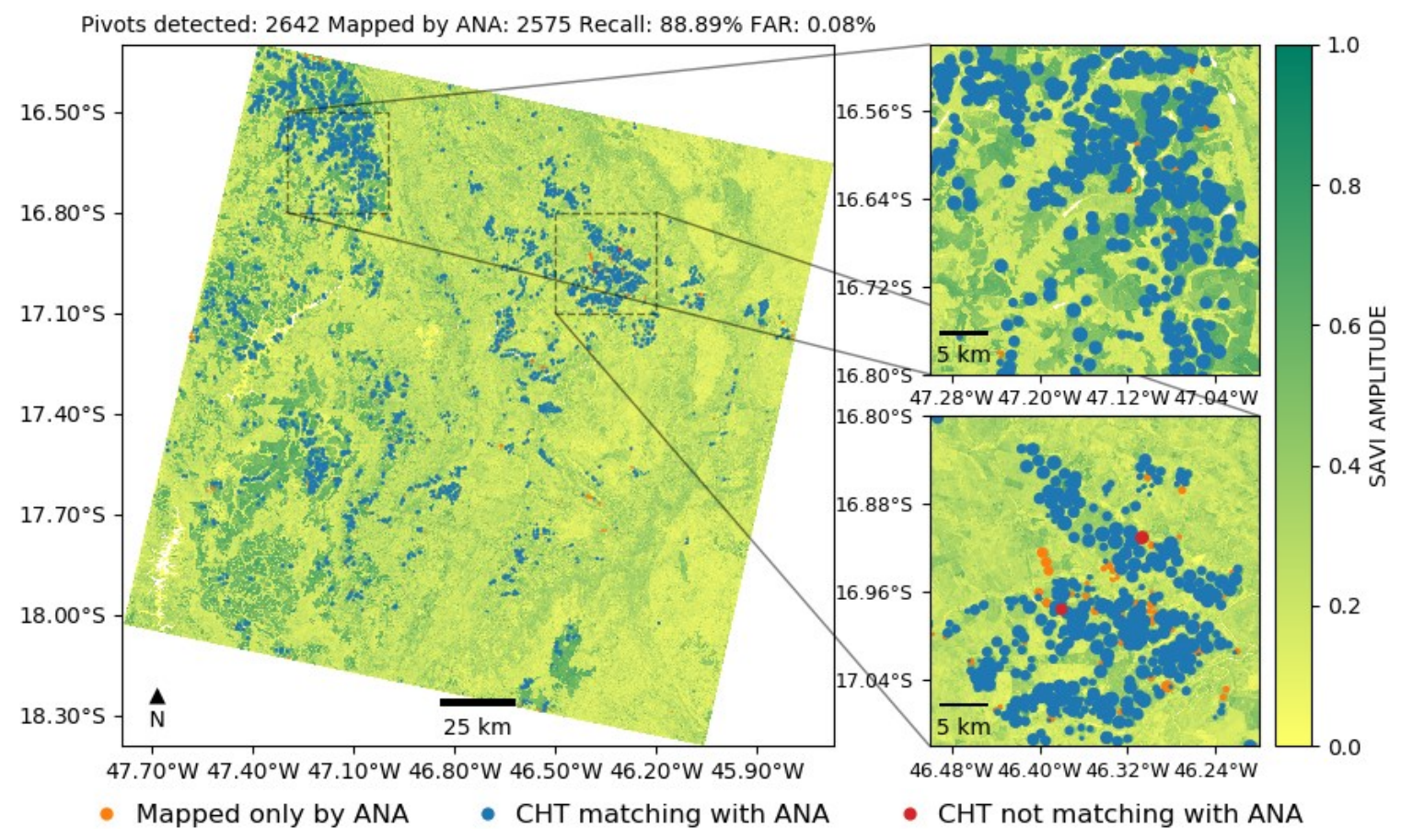

(a) BRF_ALL

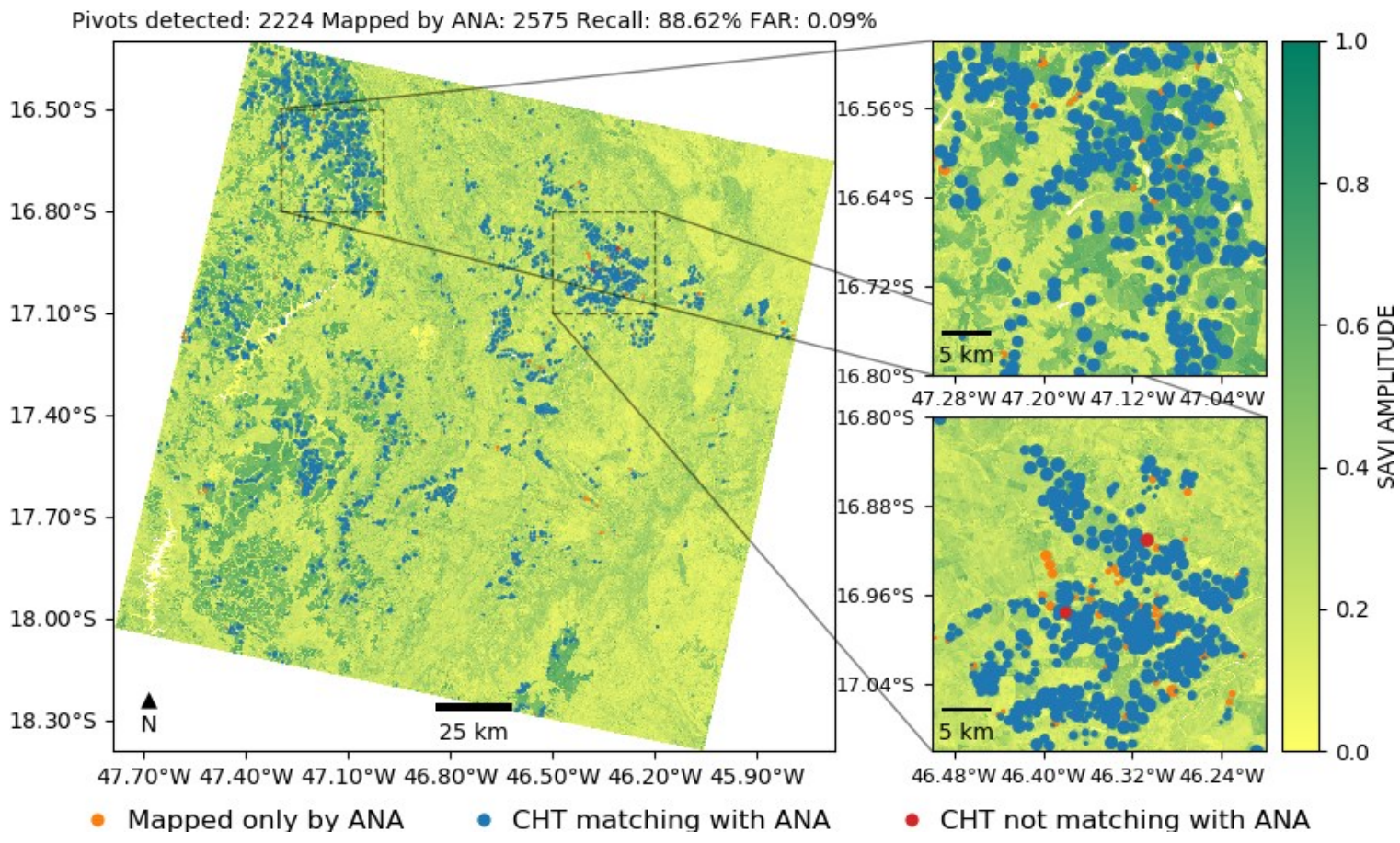

(b) BRF_ONE

Source: The authors (2021). 
Essentially, the features are selected in a manner to minimize the impurity of each tree of the RF. Our results demonstrated that the creation of decision trees for the BRF_ALL model has a major importance for spectral features from vegetation behavior against geometrical features, while the reduced number of samples offered to BRF_ONE includes geometrical features before the information of the crop type (Mode of LULC). This emphasizes that the BRF_ALL model is more suitable for handling different vegetation patterns from various regions or biomes, improving the capacity to detect pivots.

In addition, BRF_ALL can be used to classify other tiles that were not included in the prior training or even for a date where mapping does not yet exist, whereas the model based on the tiles would require a choice and the evaluation of a model with proximity to the region of interest to try to ensure an adequate response to the type of cover and vegetation in that region.

Figure 12 - Pivot recall using CHT+BRF on yearly SAVI amplitude images (2017) from tiles analyzed from Brazil.

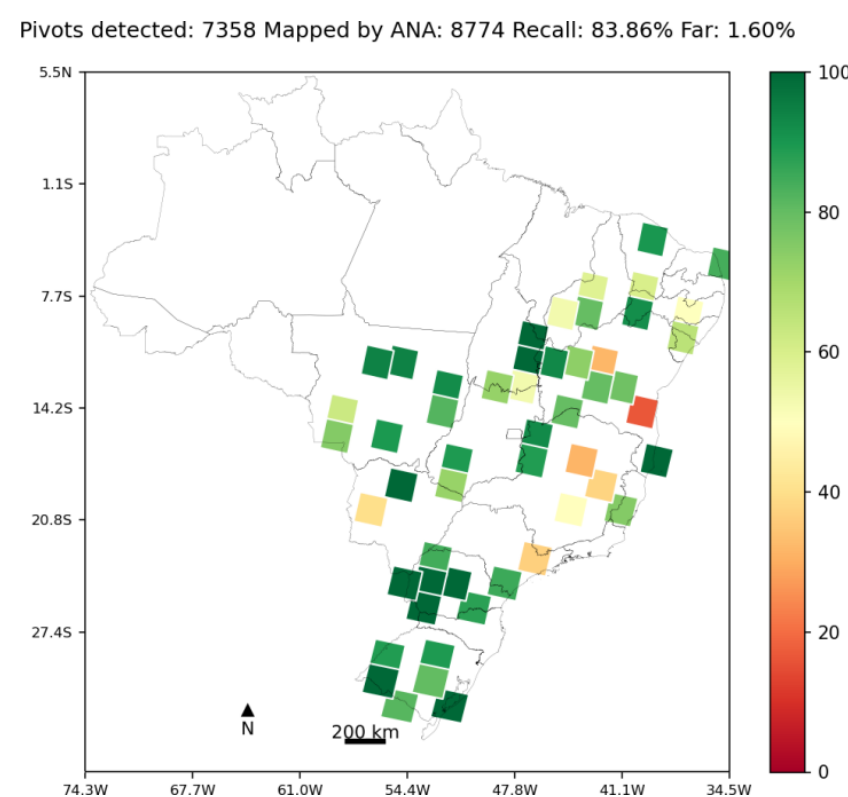

(a) BRF_ALL

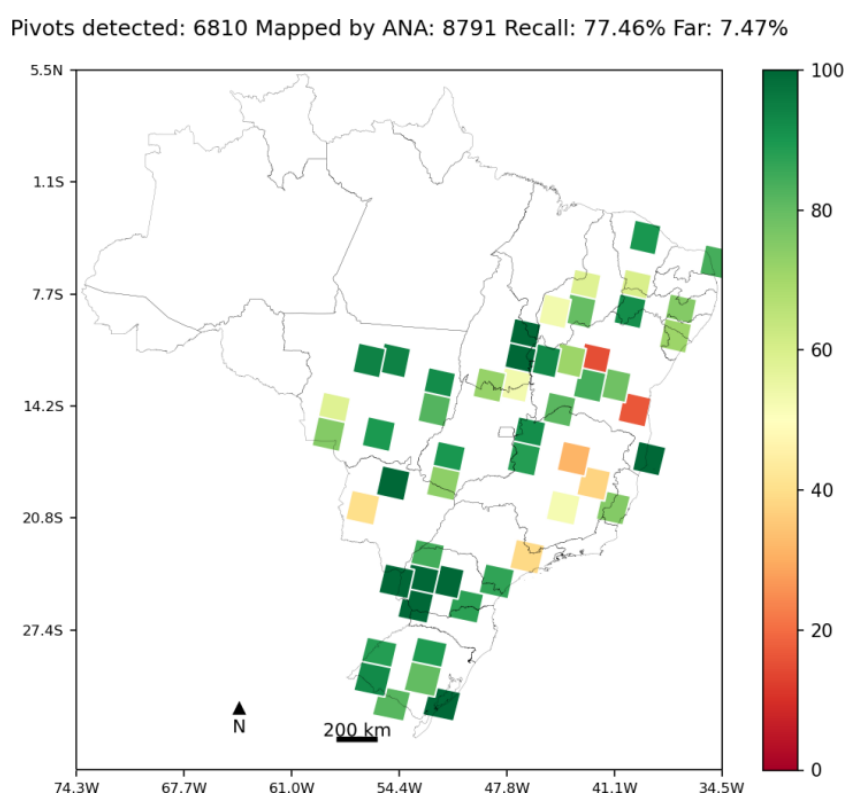

(b) BRF_ONE

Source: The authors (2021).

Figure 13 - BRF feature importance based on mean decrease impurity (MDI).

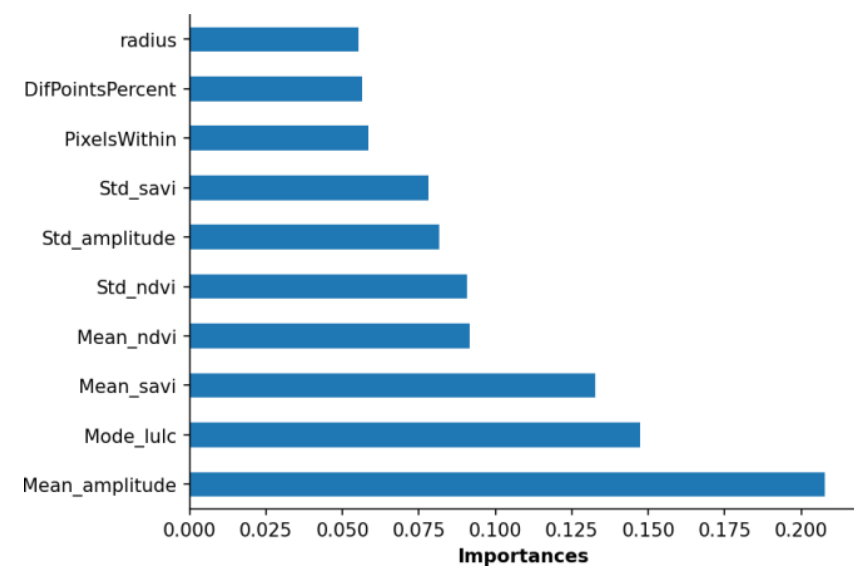

(a) BRF_ALL

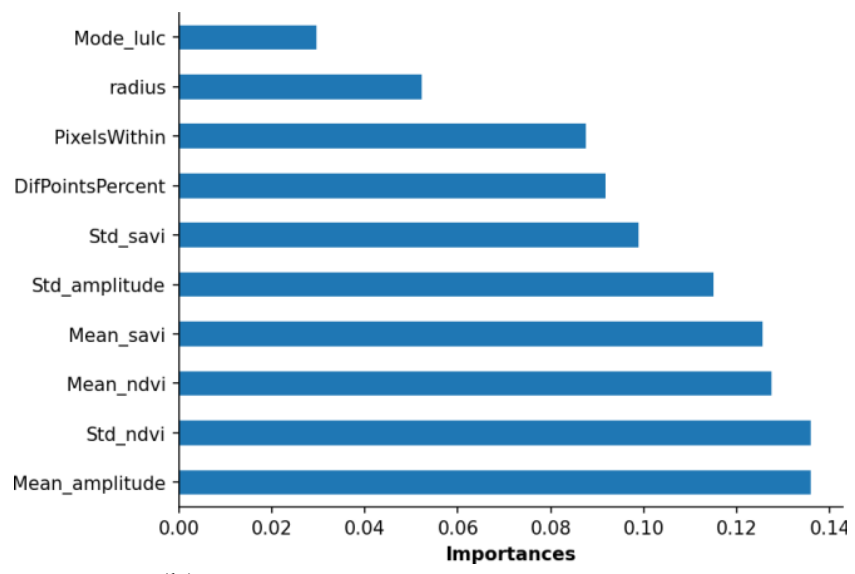

(b) BRF_ONE from path/row 220/72

Source: The authors (2021).

\subsection{Limitations to Correctly Identifying Pivots Mapped by ANA}

The official data have some characteristics that make it a challenge for the correct equivalence between the detection performed by our approach and the mapping made by ANA (Figure 14). Many 
mapped pivots have unusual shapes and radii $(40$ to $400 \mathrm{~m})$. Usually the pivots have a radius of $400 \mathrm{~m}$ (EVANS, 2001). These characteristics affect our results because the employed approach expects circular targets, and with Landsat images resolution $(30 \mathrm{~m})$, only pivot radii $(>120 \mathrm{~m})$ are detectable, limiting the equivalence between mapped and detected pivots.

Figure 14 - Challenging characteristics of ANA pivots mapping.

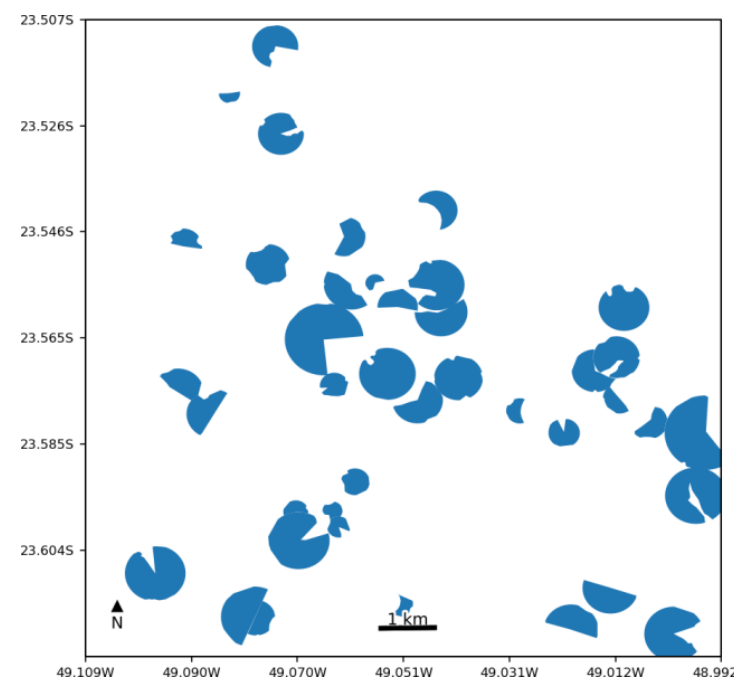

(a) Unusual and partial forms of pivots

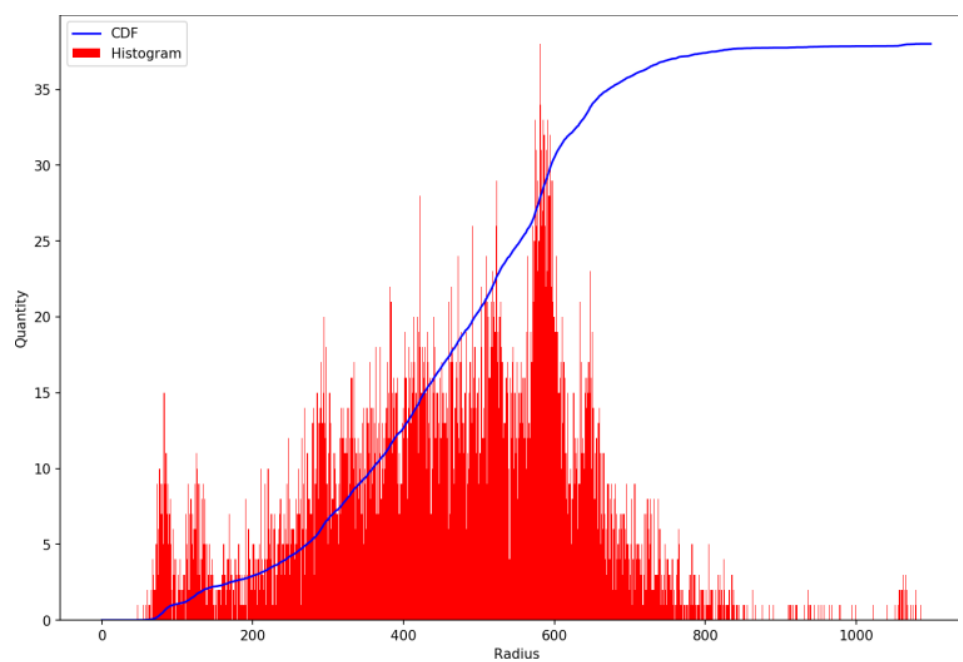

(b) Cumulative Distribution Frequency (CDF) for the radius of pivots mapped in 2017

Source: The authors (2021).

\section{DISCUSSION}

This work shows an approach to automatically identify and quantify center pivots systems based on target detection on remote sensing images of medium spatial resolution using digital processing techniques and ML models. The BRF model trained with features extracted from targets detected by CHT over SAVI amplitude tiles from Landsat 8 allowed for identifying pivots properly based on characteristics of the vegetation, where regions with a great amplitude highlight areas with agricultural activity in the period on the detriment of areas of native vegetation, and characteristics of the shapes from targets based on their delimitation through the High Pass Filter Sharr. The good accuracy achieved shows the robustness of the method in detecting pivots on a large spatial and temporal scale, which extends the results of our previous work exploring a similar idea, but based on only two scenes (RODRIGUES et al., 2020a).

The results were validated using mapping of pivots done by ANA and collaborators, and produced using visual interpretation and the manual delimitation of pivots polygons in images combined with agricultural census report, which presents significant economic and time costs (ANA; EMBRAPA, 2019). In addition to costs, this approach implies the underutilization of the potential represented by the advancement of remote sensing, as evidenced by Maranha (2018). Furthermore, the use of registration information can also lead to inconsistencies due to the omission of information on irrigators, reaching differences of 40 to $70 \%$ in relation to informed planning (BASTIAANSSEN; MOLDEN; MAKIN, 2000; GUIMARÃES; LANDAU, 2014). The main reason for this is the economic impact on charging for water resources (ANA, 2017). This emphasizes the importance of developing automatic methods to identify areas irrigated by pivots to assist in estimating water use aimed at surveillance and the charge for improper use.

The high presence of clouds and shadows over a long period can influence our results due to the masking of these unwanted pixels. Moreover, sometimes it makes it impossible to acquire images with a sufficient quality to pass through the process of radiometric and geometric corrections to generate a level 2 product of the surface reflectance image. For example, path/row 226/58 localized in the state of Amapá, Brazil had an excessive presence of clouds during 2017, making it impossible for any image to reach the 
criteria of georegistration and make this product available ${ }^{11}$. Another problem that can affect our results is the high quantity of candidate circles identified in urban areas and other heterogeneous areas, such as dunes with lagoon regions, due to the large number of edge pixels generated in these regions (RODRIGUES et al., 2020b), but this was handled with success using the Random Over Upsampling technique and the classifier BRF_ALL, filtering circles not related to pivots in these areas, independent of the climatology and LULC characteristics of the various regions of the country.

In future work, we plan to use the superiority demonstrated for the BRF_ALL approach to extend the yearly identification and quantification of pivots to other areas and dates that do not have mapping available. For this, the model will be supported with LULC information generated using the Time-Weighted Dynamic Time Warping (TWDTW) (MAUS et al., 2016) method to classify time series of vegetation indices extracted from areas identified by the CHT. This classification aims to filter the cases of false positives for nonagricultural areas based on the type of crop and number of crop cycles.

\section{CONCLUSION}

We presented a novel approach to the surveying of irrigation pivots using multistage processing. The proposed methodology enables automatic identification and quantification of center pivots systems over large regions in time and space based on target detection on remote sensing images of medium spatial resolution using digital processing techniques and ML models. The multistage method uses the temporal composition of vegetation indices to obtain SAVI amplitudes and masks of crop areas from LULC data to highlight areas with a dynamic crop activity, thereby reducing the effort and cost of not classifying targets from areas potentially not related to irrigated areas. The results demonstrate the ability of our procedure to correctly identify the pivots based on statistical information of the shape of the targets and the phenological behavior of vegetation measured through vegetation indices. This information is used to filter the circles of non-pivots detected by the CHT through a classifier (BRF_ALL) adapted for an imbalanced dataset resulting from this process. Our method presents a good agreement with the official data produced by the National Brazilian Agency and can be used to update a survey about the center pivot irrigation at the country level. The limitations of our method come from the CHT parameters, and small pivots are not detectable due to the spatial resolution of images exposed, but these issues can be overcome by adopting an optimization process for the CHT parameters and using better resolution images. The method we proposed stands out for being able to map pivots in large extensions of areas and with different climatologies.

\section{Acknowledgements}

This research was supported in part by grants 2017/24086-2 and 2018/16221-0, São Paulo Research Foundation (FAPESP), the Coordenação de Aperfeiçoamento de Pessoal de Nível Superior - Brasil (CAPES) - Finance Code 001 and the Brazilian National Council for Scientific and Technological Development (CNPq, grant 303360/2019-4). Also, we thank the National Institute for Space Research and the subproject Brazil Data Cube what is part of the Environmental Monitoring Project for Brazilian Biomes, financed by the Amazon Fund, through the financial collaboration BNDES and FUNCATE $n^{\circ}$ 17.2.0536.1.

\section{Author Contributions}

Conceptualization: M.L.R., T.S.K., G.R.Q.; Data curation: M.L.R.; Formal analysis: M.L.R., T.S.K.; Funding acquisition: T.S.K., G.R.Q.; Investigation: M.L.R., T.S.K.; Methodology: M.L.R., T.S.K., G.R.Q.; Project administration: T.S.K., G.R.Q.; Resources: T.S.K., G.R.Q.; Software: M.L.R.; Supervision: T.S.K., G.R.Q.; Validation: T.S.K., G.R.Q., M.L.R.; Visualization: M.L.R.; Writing-original draft: M.L.R., T.S.K., G.R.Q.; Writing -review \& editing: M.L.R., T.S.K., G.R.Q.

\footnotetext{
${ }^{11}$ Homepage of Landsat Collection 1 description available at https://www.usgs.gov/core-science-systems/nli/landsat/landsat-collection-1. Accessed on: February 11, 2021.
} 


\section{Conflicts Of Interest}

The authors declare no conflicts of interest.

\section{References}

AKSOY, S.; YALNIZ, I. Z.; TASDEMIR, K. Automatic detection and segmentation of orchards using very high resolution imagery. IEEE Transactions on geoscience and remote sensing, v. 50, n. 8, p. 31173131, 2012.

NATIONAL WATER AND SANITATION AGENCY (ANA). Levantamento da agricultura irrigada por pivôs centrais no Brasil - 2014: relatório síntese. Brasília, Brazil: 2016. Available at: <www.gov.br/ana/pt-br/centrais-de-conteudos/publicacoes/publicacoes>. Accessed on: Jan. 2019.

NATIONAL WATER AND SANITATION AGENCY (ANA). Atlas Irrigação: uso da água na agricultura irrigada. Brasília, Brazil: 2017. Available at: <www.gov.br/ana/pt-br/centrais-deconteudos/publicacoes/publicacoes>. Accessed on: May 2019.

NATIONAL WATER AND SANITATION AGENCY (ANA). Polos Nacionais de Agricultura Irrigada: mapeamento de áreas irrigadas com imagens de satélite. Brasília, Brazil: 2019. Available at: $<$ www.gov.br/ana/pt-br/centrais-de-conteudos/publicacoes/publicacoes>. Accessed on: Apr. 2021.

NATIONAL WATER AND SANITATION AGENCY (ANA). Atlas Irrigação: uso da água na agricultura irrigada. Brasília, Brazil: 2021. Available at: <www.gov.br/ana/pt-br/centrais-deconteudos/publicacoes/publicacoes>. Accessed on: Apr. 2021.

NATIONAL WATER AND SANITATION AGENCY (ANA); EMPRESA BRASILEIRA DE PESQUISA AGROPECUÁRIA (Embrapa). Levantamento da agricultura irrigada por pivôs centrais no Brasil (1985-2017). Brasília, Brazil, 2019. Available at: <www.gov.br/ana/pt-br/centrais-deconteudos/publicacoes/publicacoes>. Accessed on: Sep. 2019.

ARLOT, S.; CELISSE, A. A survey of cross-validation procedures for model selection. Statistics Surveys, v. 4, n. none, p. 40-79, 2010.

BARBOSA, W. O.; VIEIRA, A. W. On the improvement of multiple circles detection from images using Hough Transform. TEMA - Tendências em Matemática Aplicada e Computacional, v. 20, n. 2, p. 331-342, 2019.

BASTIAANSSEN, W. G. M.; MOLDEN, D. J.; MAKIN, I. W. Remote sensing for irrigated agriculture: examples from research and possible applications. Agricultural Water Management, v. 46, n. 2, p. $137-155,2000$.

BID, S. Change detection of vegetation cover by NDVI technique on catchment area of the Panchet Hill Dam, India. International Journal of Research in Geography, v. 2, n. 3, 2016.

BRADSKI, G.; KAEHLER, A. Learning OpenCV: Computer Vision with the OpenCV Library. O'Reilly Media, Inc., 2008.

BREIMAN, L. Random forests. Machine Learning, v. 45, n. 1, p. 5-32, 2001.

BRITANNICA ESCOLA WEB. Irrigação. $2020 . \quad$ Available at: $<$ https://escola.britannica.com.br/artigo/irrigacaoo/481588>. Accessed on: Aug. 2020.

CHEN, C.; LIAW, A.; BREIMAN, L. Using random forest to learn imbalanced data. 2004. Available at: $<$ https://statistics.berkeley.edu/sites/default/files/tech-reports/666.pdf $>$. Accessed on: Jun. 2020.

CHEN, Y.; LU, D.; LUO, L.; POKHREL, Y.; DEB, K.; HUANG, J.; RAN, Y. Detecting irrigation extent, frequency, and timing in a heterogeneous arid agricultural region using MODIS time series, Landsat imagery, and ancillary data. Remote Sensing of Environment, v. 204, p. 197-211, 2018.

COLLIGAN, T.; KETCHUM, D.; BRINKERHOFF, D.; MANETA, M. A deep learning approach to mapping irrigation: IrrMapper-U-Net. 2021. Available at: <http://arxiv.org/abs/2103.03278>. 
Accessed on: Apr. 2021.

DAVIES, E. R. A modified Hough scheme for general circle location. Pattern Recognition Letters, v. 7, n. 1, p. 37-43, 1988.

DEMARCHI, J. C.; PIROLI, E. L.; ZIMBACK, C. R. L. Análise temporal do uso do solo e comparação entre os índices de vegetação NDVI e SAVI no município de Santa Cruz do Rio Pardo-SP usando imagens Landsat-5. Raega - O Espaço Geográfico em Análise, v. 21, n. 0, 2011.

DEMBELE, F. Object detection using Circular Hough Transform. 2010. Available at: $<$ https://www.egr.msu.edu/classes/ece480/capstone/fall10/group03/index.html >. Accessed on: Jun. 2020.

DUDA, R. O.; HART, P. E. Use of the Hough transformation to detect lines and curves in pictures. Communications of the ACM, v. 15, n. 1, jan. 1972.

EIRAS, D. M. D. A.; PLETSCH, M. A. J. S.; RODRIGUES, M. L.; KARINE, R. F. G. Identificação de pivôs centrais usando composições de bandas e um método rápido de deep learning. In: BRAZILIAN SYMPOSIUM ON GEOINFORMATICS (GEOINFO), XXI, 2020, São José dos Campos, SP, Brazil. Proceedings... p. 180-185. Available at: <http://urlib.net/rep/8JMKD3MGPDW34P/43PR2H2>. Accessed on: Jan. 2021.

EVANS, R. G. Center pivot irrigation. Agricultural Systems Research Unit, North Plain Agricultural Research laboratory. USDN-Agricultural Research Service, v. 1500, 2001.

FREKEN, K.; GILLET, V. Irrigation water requirement and water withdrawal by country. Rome, Italy: 2012. Available at: <http://www.fao.org/3/bc824e/bc824e.pdf >. Accessed on: Apr. 2021.

GANDHI, G. M.; PARTHIBAN, S.; THUMMALU, N.; CHRISTY, A. NDVI: vegetation change detection using remote sensing and GIS - A case study of Vellore District. Procedia Computer Science, v. 57, p. 1199-1210, 2015.

GORELICK, N.; HANCHER, M.; DIXON, M.; ILYUSHCHENKO, S.; THAU, D.; MOORE, R. Google Earth Engine: planetary-scale geospatial analysis for everyone. Remote Sensing of Environment, 2017.

GUIMARÃES, D. P.; LANDAU, E. C. Polos nacionais de agricultura irrigada: mapeamento de áreas irrigadas com imagens de satélite. Sete Lagoas: 2014. Available at: <www.embrapa.br/biblioteca>. Accessed on: Apr. 2021.

GUO, Y.; JIA, X.; PAULL, D. Effective sequential classifier training for SVM-based multitemporal remote sensing image classification. IEEE Transactions on Image Processing, v. 27, n. 6, p. 3036-3048, 2018.

HASHIM, H.; ABD LATIF, Z.; ADNAN, N. A. Urban vegetation classification with NDVI threshold value method with Very High Resolution (VHR) pleiades imagery. The International Archives of the Photogrammetry, Remote Sensing and Spatial Information Sciences, v. XLII-4/W16, p. 237-240, 2019.

HOUGH, P. V. C. Method and means for recognizing complex patterns. 1962.

HUETE, A. A Soil-Adjusted Vegetation Index (SAVI). Remote Sensing of Environment, v. 25, p. 295309, 1988.

LEMAÎTRE, G.; NOGUEIRA, F.; ARIDAS, C. K. Imbalanced-learn: A Python toolbox to tackle the curse of imbalanced datasets in machine learning. Journal of Machine Learning Research, v. 18, n. 17, p. 1$5,2017$.

LOUPPE, G.; WEHENKEL, L.; SUTERA, A.; GEURTS, P. Understanding variable importances in forests of randomized trees. Advances in Neural Information Processing Systems, v. 26, p. 431-439, 2013.

FREITAS, S. R. C. de. Marés gravimétricas: implicações para a placa sul-americana. $264 \mathrm{f}$. Tese (Doutorado em Geofísica) - Instituto Astronômico e Geofísico, Universidade de São Paulo, São Paulo, 1998.

MARANHA, L. G. Mapeamento semiautomático de áreas irrigadas por pivôs centrais por meio de análise espacial orientada a objetos em imagem Landsat 8. 85 p. Thesis (Master in Geodetic 
Sciences) - Earth Sciences Sector. Postgraduate Program in Geodetic Sciences, Federal University of Paraná, Curitiba, 2018.

MARTINS, J. D.; BOHRZ, I. S.; TURA, E. F.; FREDRICH, M.; VERONEZ, R. P.; KUNZ, G. A. Levantamento da área irrigada por pivô central no estado do Rio Grande do Sul. IRRIGA, v. 21, n. 2, p. 300-311, 2016.

MAUS, V.; CÂMARA, G.; CARTAXO, R.; SANCHEZ, A.; RAMOS, F. M.; QUEIROZ, G. R. DE. A Time-weighted dynamic time warping method for land-use and land-cover mapping. IEEE Journal of Selected Topics in Applied Earth Observations and Remote Sensing, v. 9, n. 8, p. 3729-3739, 2016.

OZDOGAN, M.; YANG, Y.; ALLEZ, G.; CERVANTES, C. Remote sensing of irrigated agriculture: opportunities and challenges. Remote Sensing, v. 2, n. 9, p. 2274-2304, 2010.

RHODY, H. Hough circle transform. 2005. Available at: $<$ https://www.cis.rit.edu/class/simg782/schedule.htmll . Accessed on: Jun. 2020.

RIZON, M.; YAZID, H.; SAAD, P.; MD SHAKAFF, A. Y.; SAAD, A. R.; SUGISAK, M.; YAACOB, S.; MAMAT, M. R.; KARTHIGAYA, M. Object detection using circular Hough transform. American Journal of Applied Sciences, v. 2, n. 12, p. 1606-1609, 2005.

RODRIGUES, M. L.; KÖRTING, T. S.; QUEIROZ, G. R. DE. Circular hough transform and balanced random forest to detect center pivots. In: BRAZILIAN SYMPOSIUM ON GEOINFORMATICS (GEOINFO), XXI, 2020, São José dos Campos, SP, Brazil. Proceedings... p. 106-117. Available at: $<$ http://urlib.net/rep/8JMKD3MGPDW34P/43PLCP5>. Accessed on: Jan. 2021.

RODRIGUeS, M. L.; KÖRTING, T. S.; QUEIROZ, G. R. DE; SAlES, C. P.; SILVA, L. A. R. DA. Detecting center pivots in MATOPIBA using hough transform and web time series service. The International Archives of the Photogrammetry, Remote Sensing and Spatial Information Sciences, v. XLII-3/W12, p. 73-78, 2020.

SANTOS, J. É. O.; NICOLETE, D. A. P.; FILGUEIRAS, R.; LEDA, V. C.; ZIMBACK, C. R. L. Imagens do Landsat-8 no mapeamento de superfícies em área irrigada. Irriga, Special Edition, IRRIGA \& INOVAGRI, p. 30-36, 2015.

SARAIVA, M.; PROTAS, É.; SALGADO, M.; SOUZA, C. Automatic mapping of center pivot irrigation systems from satellite images using deep learning. Remote Sensing, v. 12, n. 3, p. 1-14, 2020.

SCORNET, E. Trees, forests, and impurity-based variable importance. arXiv preprint arXiv:2001.04295, 2020. Available at: <https://arxiv.org/abs/2001.04295>. Accessed on: Apr. 2021.

SHARMA, A. K.; HUBERT-MOY, L.; BUVANESHWARI, S.; SEKHAR, M.; RUIZ, L.; BANDYOPADHYAY, S.; CORGNE, S. Irrigation history estimation using multitemporal Landsat satellite images: application to an intensive groundwater irrigated agricultural watershed in India. Remote Sensing, v. 10, n. 6, 2018.

SON, N.-T.; CHEN, C.-F.; CHEN, C.-R.; GUO, H.-Y. Classification of multitemporal Sentinel-2 data for field-level monitoring of rice cropping practices in Taiwan. Advances in Space Research, v. 65, n. 8, p. 1910-1921, 2020.

SOUZA, C. M.; SHIMBO, J. Z.; ROSA, M. R.; PARENTE, L. L.; ALENCAR, A. A.; RUDORFF, B. F. T.; HASENACK, H.; MATSUMOTO, M.; FERREIRA, L. G.; SOUZA-FILHO, P. W. M.; DE OLIVEIRA, S. W.; ROCHA, W. F.; FONSECA, A. V; MARQUES, C. B.; DINIZ, C. G.; COSTA, D.; MONTEIRO, D.; ROSA, E. R.; VÉLEZ-MARTIN, E.; WEBER, E. J.; LENTI, F. E. B.; PATERNOST, F. F.; PAREYN, F. G. C.; SIQUEIRA, J. V; VIEIRA, J. L.; NETO, L. C. F.; SARAIVA, M. M.; SALES, M. H.; SALGADO, M. P. G.; VASCONCELOS, R.; GALANO, S.; MESQUITA, V. V; AZEVEDO, T. Reconstructing three decades of land use and land cover changes in Brazilian biomes with Landsat archive and Earth Engine. Remote Sensing, v. 12, n. 17, p. 2735, 2020.

SPAGNOLO, T. F. O.; COUTO JUNIOR, A. F. Expansão da agricultura irrigada por pivô central no Cerrado entre os anos de 1984 e 2008. In: BRAZILIAN SYMPOSIUM OF REMOTE SENSING (SBSR), XVI, 2013, Foz do Iguaçu, PR, Brazil. Proceedings... p. 712-719. Available at: < 
http://marte2.sid.inpe.br/col/dpi.inpe.br/marte2/2013/05.29.00.55.09/doc/p1477.pdf $>$. Accessed on: Jun. 2019.

TRINCA, V. F.; AMENDOlA, E. C.; HeRnAndeZ, F. B. T.; COAGUilA, D. N.; FEITOSA, D. G. Evolução da área irrigada por pivô central no Oeste Paulista. In: INOVAGRI INTERNATIONAL MEETING, III, 2015, Fortaleza, CE, Brazil. Proceedings... p. 712-719. DOI. 10.12702/iii.inovagri.2015-a268.

UNITED STATES GEOLOGICAL SURVEY (USGS). Landsat Surface Reflectance Quality Assessment. Available at: <https://www.usgs.gov/land-resources/nli/landsat/landsat-surface-reflectance-qualityassessment?qt-science_support_page_related_con $=0 \# q$ t-science_support_page_related_con $>$. Accessed on: Jun. 2020.

YAN, L.; ROY, D. P. Automated crop field extraction from multi-temporal web enabled Landsat data. Remote Sensing of Environment, v. 144, p. 42-64, 2014.

YANG, H.; LUO, J.; SHEN, Z.; WU, W. A local voting and refinement method for circle detection. OptikInternational Journal for Light and Electron Optics, v. 125, n. 3, p. 1234-1239, 2014.

YIN, H.; UDELHOVEN, T.; FENSHOLT, R.; PFLUGMACHER, D.; HOSTERT, P. How Normalized Difference Vegetation Index (NDVI) trends from Advanced Very High Resolution Radiometer (AVHRR) and Système Probatoire d'Observation de la Terre VEGETATION (SPOT VGT) time series differ in agricultural areas: an inner Mongolian case study. Remote Sensing, v. 4, n. 11, p. 3364-3389, nov. 2012.

YUEN, H. K.; PRINCEN, J.; ILLINGWORTH, J.; KITTLER, J. A comparative study of Hough transform methods for circle finding. In: ALVEY VISION CONFERENCE ,V, 1989, Reading, Berkshire, England, UK. Proceedings... p. 169-174. DOI. 10.5244/C.3.29.

ZEILHOFER, P.; ÁlVARES, A. L. P.; DA SILVA, G. F.; KLEMP, S. M. Técnicas de reconhecimento de formas para identificação de áreas de irrigação por imagens de satélite. In: BRAZILIAN SYMPOSIUM OF REMOTE SENSING (SBSR), XIII, 2007, Florianópolis, SC, Brazil. Proceedings... p. 6291-6298. Available at: < http://marte.sid.inpe.br/col/dpi.inpe.br/sbsr@80/2006/11.15.23.53.06/doc/62916298.pdf>. Accessed on: Jun. 2019

ZHANG, C.; YUE, P.; DI, L.; WW, Z. Automatic identification of center Pivot irrigation systems from Landsat images using convolutional neural networks. Agriculture, v. 8, n. 10, p. 147, 2018.

\section{Lead author's biography}

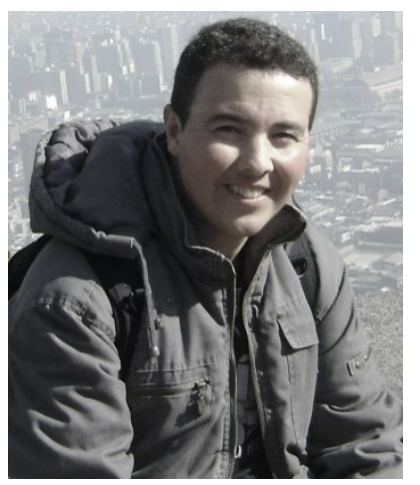

Marcos Lima Rodrigues, Caçapava-SP, 1977. M.L.R. holds a degree in Scientific Computation from University of Taubaté, specialization in Tecnology and Information Systems from Federal University of $\mathrm{ABC}$ and Master in Applied Computing from the National Institute for Space Research (INPE). He has experience in Geosciences, with emphasis on Meteorology and Remote Sensing to development of algorithms for environmental variables such as: surface solar radiation, sunshine duration, ultraviolet index and cloud classification through physical models and satellite images; weather radar precipitation. He currently holds a Ph.D candidate at Posgraduation of Applied Computing at INPE, within the Earth Observation and Geoinformatics Division.

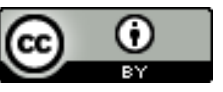

Esta obra está licenciada com uma Licença Creative Commons Atribuição 4.0 Internacional - CC BY. Esta licença permite que outros distribuam, remixem, adaptem e criem a partir do seu trabalho, mesmo para fins comerciais, desde que lhe atribuam o devido crédito pela criação original. 